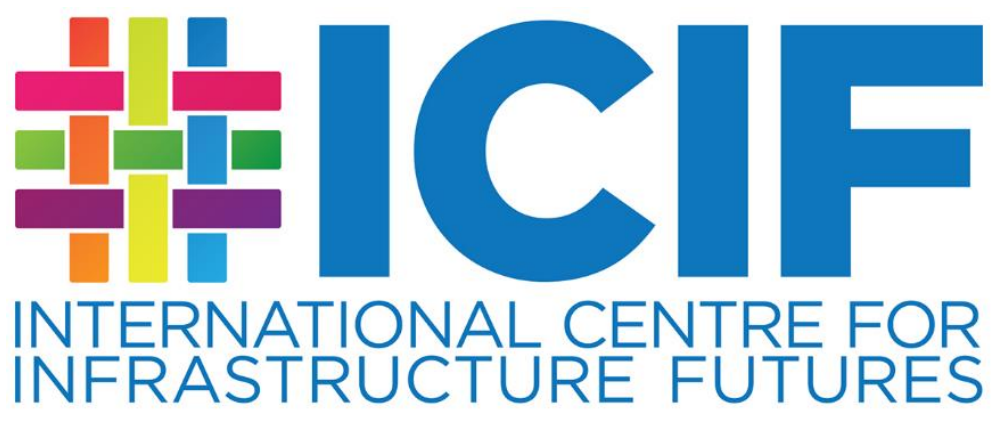

Investigation into the Development of a Framework for the Identification and Appraisal of Infrastructure Interdependencies with Application to Critical UK Infrastructure:

Technical Report for Infrastructure UK.

\title{
Development of a Proposed Interdependency Planning and Management Framework
}

Final Report Published 30th October 2014 DOI: $10.14324 / 20141455020$ 


\section{Report Authors}

Dr Ges Rosenberg, Research Manager, Systems Centre \& Department of Civil Engineering, University of Bristol, Bristol BS8 1UB, United Kingdom. (Email: ges.rosenberg@bristol.ac.uk).

Dr Neil Carhart, Research Associate, Systems Centre \& Department of Civil Engineering, University of Bristol, Bristol BS8 1TR, United Kingdom. (Email: neil.carhart@bristol.ac.uk).

Dr Andrew Edkins, Senior Lecturer, The Bartlett School of Construction \& Project Management, Faculty of the Built Environment, 1-19 Torrington Place, UCL, London, WC1E 7HB

(Email: andrew.edkins@ucl.ac.uk).

Dr John Ward, Senior Research Associate, The Bartlett School of Construction \& Project Management, Faculty of the Built Environment, 1-19 Torrington Place, UCL, London, WC1E 7HB. (Email: eric.ward@ucl.ac.uk).

\section{Acknowledgement}

This report comprises a case study for a programme of research entitled 'The Development of a Framework for the Identification and Appraisal of Infrastructure Interdependencies with Application to Critical UK Infrastructure', completed on behalf of Infrastructure UK. The development project was led Prof. Brian Collins ${ }^{1}$ and Prof. Patrick Godfrey ${ }^{2}$ as Principal Investigators, and was funded by Infrastructure UK, University College London and the University of Bristol. The authors are grateful to the International Centre for Infrastructure Futures for publishing the final report and would like to record their special thanks to David Penhallurick and Richard Ploszek (both Infrastructure UK) for their resolute support and encouragement throughout.

\section{Disclaimer}

The views and recommendations expressed in this report are solely those of the authors and do not represent Government policy.

\footnotetext{
${ }^{1}$ Professor of Engineering Policy, UCL; Director, International Centre for Infrastructure Futures (ICIF).

2 Professor of Systems Engineering; Director of the Systems Centre, University of Bristol.
} 


\section{Contents}

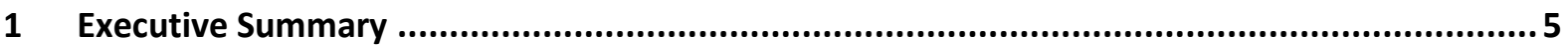

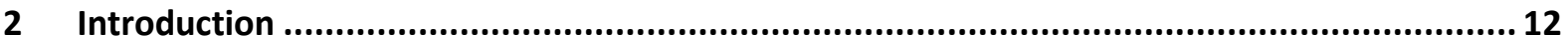



2.2 Emergence of Unplanned Interdependence.................................................................... 13

2.3 An Interdependency Planning \& Management Framework ............................................ 13

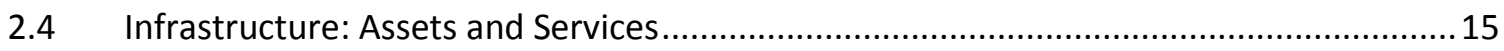

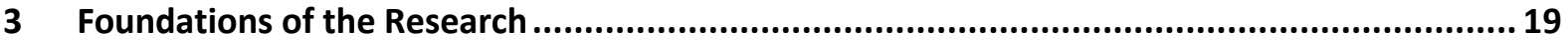

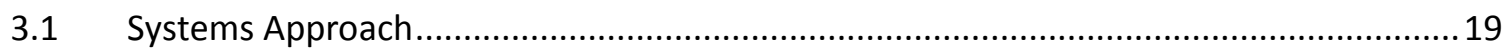



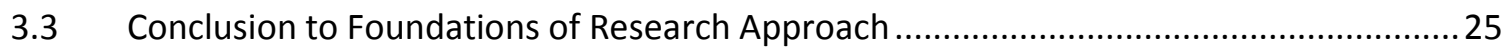

4 A Proposed Framework for Infrastructure Interdependency Planning \& Management .......... 27

4.1 Delivering Stewardship of the Network of Infrastructure Assets ....................................27

4.2 The Role of Project Management in the Consideration of Interdependencies for

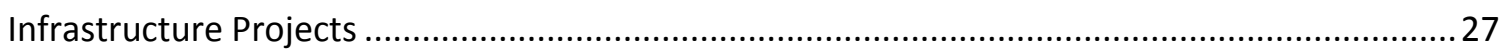

4.3 The Interdependency Planning and Management Process ............................................. 30

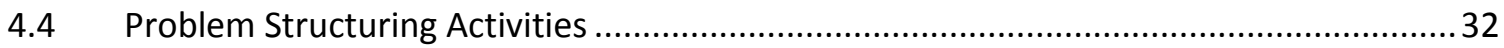

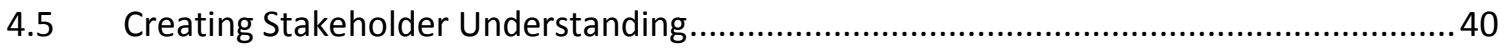

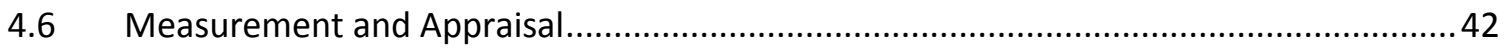

5 Interdependency Planning and Management Framework Testing ......................................... 44

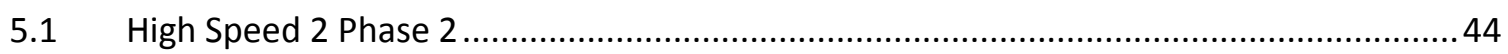

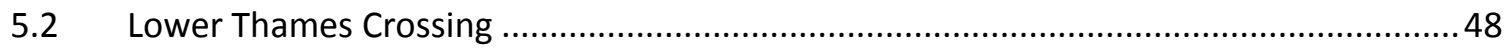

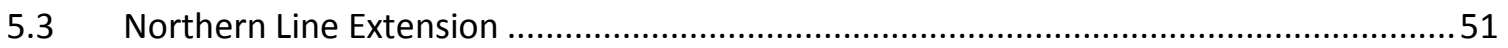

5.4 Engineering the Future Infrastructure Timelines............................................................. 56

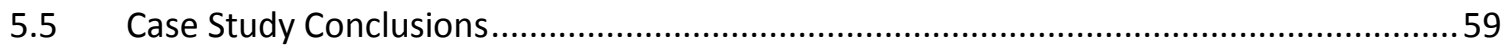

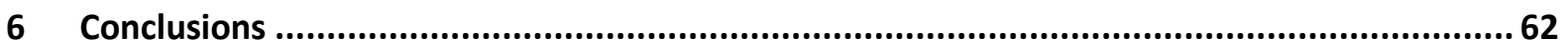

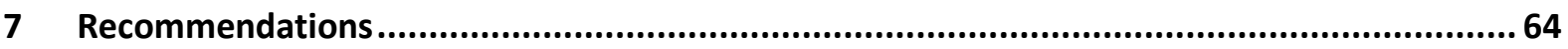

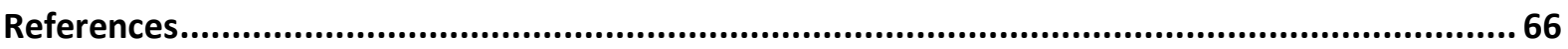

Appendix A Interdependency Planning and Management Framework Specification .................69






\section{List of Figures}



Figure 2 - An Overview of the Interdependency Planning and Management Framework .................. 31

Figure 3 - Schematic of interdependency Planning and Management Framework .............................. 31

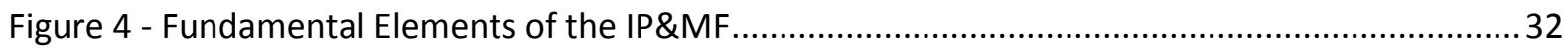

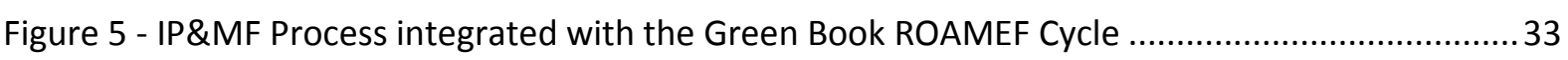



\section{List of Tables}

Table 1 - Infrastructure Sectors

Table 2 - Preliminary Infrastructure Sectors for Proposed Framework

Table 3 - Interdependency Characteristics 


\section{Executive Summary}

The need for more and better infrastructure is an issue that affects all countries. There is an estimated global need for infrastructure investment of $\$ 57$ trillion by 2030 to simply keep pace with current global rates of GDP growth [1]. This infrastructure needs comprises a wide variety of types located in many different locations, both on the planet and in space.

Much of this infrastructure is highly coupled: natural and built assets are materially interconnected, both with each other and with the socio-economic systems in which they are located. However, ownership and responsibility and accountability, together with current planning, project appraisal and design processes for major infrastructure systems are failing to identify and capture the potentially valuable interdependencies which could be exploited to enhance the efficiency and effectiveness of infrastructure, nor are they systematically identifying potentially hazardous and economically damaging interdependencies. It is also evident that interdependencies, and the attendant benefits and costs, frequently emerge without prior intent to identify or utilise them, even in cases where they may reasonably have been forecasted.

Focusing on the UK, much of its infrastructure was built some time ago, with a significant amount created in the Victorian era and now showing increasing signs of ageing whilst coping with rapidly changing demands upon it. This situation is recognised in the HM Treasury National Infrastructure Plan 2011 [2] which characterises the UK's approach to the development of infrastructure of national importance as having been "fragmented and reactive", and that "opportunities to maximise infrastructure's potential as a system of networks have not been exploited" (p5). Despite this, National Infrastructure remains "a major determinant of growth and productivity" (p5), and an instrument for geographically rebalancing the economy.

Infrastructure provides a vital role in supporting our society and economy, but how we consider infrastructure is not as clear, with it being seen variously as collections of interlinked assets, separate and distinct networks or pervasive systems. This partial and fragmented appreciation of infrastructure increasingly recognised as missing much that this infrastructure does and can do for us as a nation. This is brought into sharp focus when a proposed infrastructure project is considered for investment appraisal. This report is the result of a growing recognition that the current consideration and approach is limited and is missing potential opportunities arising from considering infrastructure in new lights.

For example, in previously reported work $[3,4]$, the OMEGA Centre concluded from a global study that infrastructure should be viewed as an 'open system', thereby allowing delivery teams to accommodate internal and external socio-economic, natural and technical interactions in the planning, appraisal and design processes. This also points to the importance of effective and early engagement with a broad set of key stakeholders, a critical factor in the specification, planning, and appraisal of infrastructure and for the identification of immediate and downstream interdependencies. Similarly, defining infrastructure development in terms of narrowly framed monetary costs and monetised benefits was found to unduly constrain the processes of infrastructure planning, appraisal and design; limiting efforts to identify a more complete set of potential interdependencies and seek benefit through their exploitation. 'Soft' factors such as governance structures, regulatory regimes, policy frameworks, institutions and organisational learning, were also 
found to be highly important determinants of the likely success of infrastructure development. This work is complementary to that produced by Frontier Economics [5] which similarly appreciated the wide range of benefits that infrastructure provides in indirectly supporting economic and social activity and prosperity..

Set within these contexts, this report sets out a preliminary architecture for an Interdependency Planning and Management Framework (IP\&MF) framework for the identification and appraisal of infrastructure interdependencies with applicability to a wide range of national infrastructure. It frames this as a 'wicked' problem [6, 7] requiring a systematic approach capable of balancing the existing assets (the 'hard' systems associated with legacy assets) and 'soft' factors and services (such as institutions, organisations, perceptions of need and design codes), with the future infrastructure needs and assets. The proposed approach aims to be equally applicable for the continual incremental renewal and retrofitting of existing infrastructure, as well as for the planning and commissioning of new infrastructure: it therefore recognises the need to continually assess and manage the interdependencies between infrastructure assets over their lifetime, which can extend over many decades which are beyond standard forms of predictive forecasting.

The IP\&MF framework is founded on a holistic, open systems-based approach that views critical infrastructure as an entwined network, or 'system of systems', created iteratively in response to various 'stakeholder purpose'. It proposes an approach by which to guide practitioners and stakeholders in identifying existing and potential infrastructure dependencies and interdependencies, and therefore provide opportunities to enhance Value-for-Money, efficiency, effectiveness, sustainability and resilience (as recommended by the Council for Science and Technology in [8]).

The UCL OMEGA Centre's research also emphasises the need to manage infrastructure development as an 'organic' phenomena in which there are emerging risks and opportunities generated by the external turbulent environment in which many infrastructure projects and assets sit. Implicit in this is that the longevity of infrastructure assets requires stakeholders to accept the inability to accurately predict the longer term future. A key principle underpinning the proposals in this report therefore is that effective and efficient strategic governance or 'stewardship' of infrastructure requires a shift away from an individual asset management perspective. Instead it requires a wide range of institutions and enterprises to collaborate in developing a coherent framework of policies, plans, processes and institutions to guide future infrastructure investment and planning.

The IP\&MF proposed in this report has been designed to sit alongside, and build upon the existing ROAMEF $^{3}$ project appraisal and evaluation cycle set out in the HM Treasury Green Book[9].

At the core of the proposed framework is a strategic set of systems thinking principles, processes and tools which aim to drive infrastructure proposers and delivery teams to look for a) beneficial interdependencies with other infrastructure and policies (synergies), and b) problematic dependencies (systemic vulnerabilities or conflicts) to be managed. By exploring, and potentially expanding the boundary to the problem, the infrastructure delivery team would be required to identify the principal 'soft' and 'hard' systems with the potential to interact with the infrastructure

${ }^{3}$ Rationale, Objectives, Appraisal, Monitoring, Evaluation and Feedback (ROAMEF) constitute the six stages of the policy cycle, of which Appraisal and Evaluation are a part 
system being developed. This approach requires policy makers, economists, planners and engineers to adopt three principles in particular:

1. That infrastructure development requires a holistic, open systems view of infrastructure, and in this regard to recognise and adopt a 'system of systems' perspective.

2. That all 'hard' infrastructure systems are developed within a framework of 'soft' systems comprising policies, processes and practices, coupled with the institutions, organisations and people that define and implement them.

3. To question and explore the accepted and/or perceived system boundary for an infrastructure development in order to engage with a wider range of stakeholders and create the potential for innovative project scoping and design options.

The IP\&MF proposed in this report is capable of supporting both 'broad-brush' strategic appraisals at the start of the planning and design processes, as well as more complex and detailed engineeringorientated assessments later on in the project life-cycle. Such assessments of interdependency could be identified either 'top-down' from very general overview of the interdependencies, or alternatively could be a representation developed 'bottom-up' from an aggregation of more detailed analyses.

The proposed framework can be summarised by three groups of activities:

\section{Problem Structuring}

2. Measurement and Appraisal

\section{Creating Stakeholder Understanding.}

These activities are undertaken iteratively and in some cases concurrently, and are informed by an evolving and maturing knowledge base in Interdependency Planning and Management. In the context of the framework problem structuring can be broadly described by eight activities.

1. Explore the system boundary and policy context according to an open systems thinking approach. This preliminary activity formally embodies the three principles above into the framework process. This provides greater opportunity for creative thinking in infrastructure planning, appraisal and design, and to promote participation from a broad group of relevant stakeholders.

2. Establish and frame the core development needs. This is necessary to ensure that criteria of success for the core development goal can be established, and therefore that the cumulative effects of beneficial and adverse interdependencies can be appropriately framed and assessed in the appraisal process.

3. Explore the boundary and context to the infrastructure needs. It is necessary to creatively and systematically search and reveal the relationships between the defined need for the core intervention and other socio-economic and environmental needs and policy goals which comprise the 'context'.

4. Identify the architecture of the infrastructure network. The systems architecture provides a high-level, conceptual model that depicts the structure of a given systems, and the interactions it has with other hard and soft systems. This captures and represents the planned development and its relationships with other infrastructure. It allows for the general nature of the infrastructure development to be communicated with stakeholders, and provides a platform for identifying interdependencies. 
5. Identify interactions with additional socio-economic and environmental needs. Drawing on the previous activities, this requires engagement with a broad spectrum of infrastructure stakeholders to identify shared needs and additional needs which could be met by the core infrastructure development. The outcome of this should continue the development of the problem structuring and modelling initiated in the earlier activities. These should adequately capture and describe a set of positive (beneficial) and negative (adverse) interdependencies comprising opportunities and risks for consideration as part of the business case and in the planning, engineering design and appraisal processes.

6. Identify opportunities to develop beneficial interdependencies. This may occur when defining the infrastructure need, when setting the objectives and appraising a project, during implementation of an infrastructure project, or during post-project upgrade.

7. Identify risks from adverse interdependencies. The risks from adverse interdependencies should be identified throughout the planning, design, implementation and operation of the infrastructure, and it is particularly beneficial to apply them early on before project goals have been substantially set.

8. Define objectives for interdependency planning and management. The framework then calls for planning and appraisal options based around the identified interdependencies. This will be guided by decisions over which beneficial interdependencies should be incorporated into the scope of core infrastructure project, which is itself based on evidence presented by the appraisal process.

The measurement and appraisal leg of the framework can be summarised into three activities:

1. Establish criteria to validate interdependencies. The value of the beneficial interdependencies should be assessed and validated, and a MCA is recommended for this step. A range of holistic sustainability appraisal tools have been developed, generally based around PESTLE and other sustainability checklist approaches, and these provide a useful means of identifying suitable appraisal criteria. Similarly criteria for assessing the adverse impacts from negative interdependencies will be need to be established at this stage in the process, for example defining the levels of probability and impact commonly used in probability-impact approaches to risk assessment.

2. Gather evidence and appraise interdependencies. Evidence to support the appraisal of interdependencies will be compiled throughout the stages of 1) exploring the systems boundary and context, 2) the creation of stakeholder understanding and 3) during the identification of positive and negative interdependencies. The approach to appraising interdependencies should be consistent with the overall appraisal process for the main project.

3. Review business case against maturity of interdependency management. For successful planning and management of infrastructure interdependencies, it is important that the core business case for a proposed infrastructure development should be reviewed.

The successful application of these two stages relies upon the engagement of a wide selection of stakeholders. This relates then to the third group of activities: creating stakeholder understanding. This is described below through the performance of two activities:

1. Identify cross sector stakeholders for potential collaboration. Effective and early engagement with key stakeholders is critical in infrastructure specification, planning, appraisal and delivery as 
a means of identifying a more comprehensive and robust set of the beneficial and adverse interdependencies. It prevents downstream major changes and discourages the premature adoption of solutions dominated by one specific technology as well as helping to avoid the premature discarding of options.

2. Develop interdependency planning and management practice. The IP\&MF recognises that there is a need to embed a context-dependent learning process that can inform the development of strategic policy, governance/stewardship and valuation of infrastructure and associated interdependencies on a continual basis.

The proposed IP\&MF framework is the result of a research project comprising two stages, each with sub-stages. The first stage involved the scoping work necessary to identify the basis of what a framework would need to comprise and drew upon existing practice, work carried out at the Systems Centre at University of Bristol, and input from both the OMEGA Centre's global research on mega transport infrastructure and project management from The Bartlett, UCL's faculty of the built environment. Stage one also included a stand-alone task to investigate the potential interdependency arising from the possible inclusion of the provision of dormant fibre optic cabling along the proposed route of HS2 phase 1. Stage two was to operationalize the proposed framework via testing initially on four (later revised to three) specified cases listed in the National Infrastructure Plan. Three of the cases involved are real large-scale transport-led infrastructure projects. This provided an opportunity to test and develop the framework while also offering benefits to the chosen infrastructure projects.

The Case Studies demonstrated that the framework provided a means to identify, characterise and evaluate interdependencies which can then be subjected to additional detailed study based on their valuation. They show, be revealing multiple interdependencies, that there is potential for the identification and management of interdependency within and between infrastructure projects which goes beyond the status quo.

The first case study application looked Phase Two of the proposed High Speed 2 rail network, from Birmingham to Manchester and Leeds [10]. The facilitated interaction of a wide range of infrastructure stakeholders revealed that the High Speed $\mathbf{2}$ Phase $\mathbf{2}$ corridor could be used to provide or assist in delivering other potentially valuable infrastructure projects as an 'agent of change'. This includes providing: additional electricity distribution capacity into Sheffield and Manchester; the capability for inter-regional water transfer at key locations; the capability for additional flood protection; and, the capability for distributing additional ICT infrastructure.

The second case study, a desk study of the Lower Thames Crossing project [11] identified and assessed a number of opportunities arising from exploiting additional interdependencies or engineering new interdependencies. Appreciating the full impact of these requires a view of the project that goes beyond its conceived boundary and purpose as a solution to a transport challenge. For example the crossing could provide the capability for additional electricity generation and utility distribution. It could help facilitate the construction of additional flood defences and, as part of its construction, provide a use for waste products such as tyres. There are opportunities for positive and negative interdependencies to arise between the crossing and several regeneration projects in the area, even though these are ultimately loosely coupled from one another.

The third case study, an in depth study of the Northern Line Extension project [11], provided additional insight into the reasons why such interdependencies are not widely considered. It was 
observed that the appraisal process for the project was based exclusively on the line haul without adequate consideration of the potential interactions with the other infrastructure elements required to achieve the wider, but this time closely associated, urban regeneration policy goals. The fact that the Northern Line Extension project is relatively tightly coupled with the regeneration schemes, yet these interdependencies were still not appropriately considered, is perhaps evidence that the current approach is not adequate and encourages a closed-system view. The study of the Northern Line Extension project also revealed a dependence on Cost Benefit Analysis and a narrow appreciation of the wider stakeholder needs. These can unduly constrain a project, discouraging an appreciation for the wider costs, benefits and requirements, and hindering the consideration of interdependencies.

In addition to these case studies looking at the application of the framework to specific infrastructure projects, elements of the framework were also applied in a multi-disciplinary stakeholder workshop to investigate the interdependencies between policies and projects identified in Engineering the Future's Infrastructure Timelines [13, 14]. The IP\&MF was presented at the International Symposium on Next Generation Infrastructure in 2013 to elicit more general feedback on the proposed approach from an international audience [15].

In terms of more direct conclusions, the following points are made:

1. An IP\&MF has been developed and implemented comprising principles, practice and organisational maturity, and example methods and tools.

2. A description of an IP\&MF process has been presented, together with an implementation of this based around PESTLE, matrix mapping and MCA, but noting that other tools could be used to implement the framework.

3. Elements of the framework have been tested in the three final case studies. The degree of testing has not been as extensive as we would have liked, and not all elements of the framework have been tested in all case studies.

4. The failure to conduct full testing on all three cases reveals the essential and implicit need for the leading project players to understand and appreciate the potential value of conducting such an interdependence search exercise.

5. The evidence from the OMEGA Centre research clearly indicates the need for engagement and involvement with a wide range of stakeholders early on in the project lifecycle, before the project is committed in terms of definition and scope.

6. The OMEGA Centre's previously completed research led to their proposal of a policy-led MCA approach. This is strongly supportive of the open systems approach, with central focus on the importance of understanding the various contexts in which the proposed project is set.

7. The importance of interdependency management is now beginning to be widely recognised including by Government. This is evidenced in recent reports from both credible authors and on nationally significant projects (e.g. the recent HS2 Phase 2 consultation).

8. In conducting this research the research team can find no evidence of any other country that would be comparable to the UK where the thinking and actions related to interdependency is as advanced. Countries like Singapore and territories like Hong Kong have considered such 
interdependencies, but they have significantly different histories and national profiles to the UK. We believe that this work puts the UK in the vanguard.

9. Recommendations have been made for implementation of an Annex to the Green Book.

The four recommendations arising from this work can be summarised as:

Recommendation 1: That a stewardship function is established by Government with the purpose of overseeing the integration of infrastructure planning, delivery and operation.

Recommendation 2: That an Open Systems approach be used to underpin the Green Book Interdependency Planning and Management Process.

Recommendation 3: That there is a need to embed learning and maturity modelling in order to inform the development of policy and practice in planning and managing infrastructure interdependency.

Recommendation 4: That business models and practices are needed which seek to promote openness and collaboration in the creation and operation of infrastructure. 


\section{Introduction}

\subsection{A Legacy of Fragmented and Ageing Infrastructure}

Throughout its development and especially since the Victorian era of substantial infrastructure creation, the UK's infrastructure has been increasingly conceptualised and treated for the main part as a series of complicated separable technical challenges. The focus of the relevant professions (engineers, architects, project managers and economists) has been on commissioning and operating individual infrastructure assets; each of which has been specified and appraised at a given juncture against a current perceived need, for a tightly defined life-expectancy, and then designed, built and operated by an individual industrial sector. For example, the National Infrastructure Plan 2011 [2] characterises the UK's approach to the development of infrastructure of national importance as having been "fragmented and reactive", noting that "opportunities to maximise infrastructure's potential as a system of networks have not been exploited" (p5). Despite this, National Infrastructure remains "a major determinant of growth and productivity" ( $\mathrm{p5}$ ), and an instrument for geographically rebalancing the economy. This is a view held internationally as expressed by the OECD: "Infrastructures are the very foundation of modern economies and societies. Energy, transport, water, telecommunications, all will continue to be essential to future development and growth." [16]

The UK's infrastructure is also ageing, in many instances it is operating beyond its expected design life, added to which socio-economic demands placed upon it are rapidly increasing and changing, leading to calls for investment to modernise and expand the UK's infrastructure asset base. Ownership of infrastructure and patterns of governance are similarly segmented into industrial sectors, adding both institutional and policy barriers to resolve if a more integrated approach is to be implemented.

A fragmented approach to infrastructure ownership, governance and operation militates against the possibility of improving the efficiency and effectiveness of infrastructure for a number of reasons. Firstly, current policies and processes governing the planning, appraisal, design and operation of infrastructure are incapable of identifying stakeholders with common interests, and therefore discourage the building of collaborative governance structures and enterprises that could span industrial sectors. Secondly, the narrow project-based approach to the financing and delivery of infrastructure creates processes and structures which militate against the systematic identification of potentially valuable interdependencies and the exploitation of these to enhance the efficiency and effectiveness of infrastructure and its delivery. Thirdly, the same project-based delivery mechanisms do not support the systematic identification of potentially hazardous and economically damaging interdependencies and adverse cumulative impacts. Finally current preferred options appraisal techniques, such as Risk and Cost-Benefit Assessment (CBA) techniques, do not provide a means of valuing the benefits accruing from existing and potential interdependencies, and this narrows the focus of the planning and engineering design process to the delivery of primary functional goals. In such a way, the current approaches can undermine the long term benefit that infrastructure has the potential to provide. 


\subsection{Emergence of Unplanned Interdependence}

The policy perspective of infrastructure being considered in distinct silos is contrary to experience in the real-world, where it is apparent that infrastructure is highly coupled, and natural and built assets are highly interconnected, both with each other and with the socio-economic and environmental systems in which they are located. It is also evident that interdependencies, and the attendant benefits and costs, frequently emerge without prior intent to identify or utilise them, even in cases where they may reasonably have been forecasted.

The necessity of valuing the opportunities and risks of shared infrastructure assets as part of the evaluation of infrastructure spending has already been established by HMT [17]. In addition to this the National Infrastructure Plan [2] highlights the importance of considering interdependency between infrastructure projects, requiring pilot reviews of interdependency during the design and engineering phases of projects. Thus, there is an established need to be able to identify and evaluate the benefits, risks and costs of existing and potential interdependency between infrastructure projects and assets.

There are many methods for modelling the interdependency between infrastructure elements, each serving a specific purpose and providing a different conception of what interdependency means in relation to infrastructure. Some differing conceptions of infrastructure interdependency can be attributed to the multiple viewpoints of the stakeholders responsible for commissioning, financing, planning, designing, building, operating and using infrastructure. Carhart and Rosenberg [18] present a taxonomy of infrastructure interdependency and dependency, comprising sources and generic characteristics, and review a range of approaches used to model interdependency.

\subsection{An Interdependency Planning \& Management Framework}

The research and development activities described in this report have been completed under contract to HM Treasury by the Systems Centre at the University of Bristol working in partnership with The Bartlett faculty of the built environment at UCL. It responds to a requirement to develop a framework for the identification and appraisal of infrastructure interdependencies with applicability to a wide range of critical infrastructure, referred to as the Interdependency Planning and Management Framework (IP\&MF).

The approach aims to be equally applicable for the continual incremental renewal and retrofitting of existing infrastructure, as well as for the planning and commissioning of new infrastructure. It seeks to provide a systematic approach by which to guide practitioners in identifying existing and potential dependencies and interdependencies present in infrastructure, its sub-systems and elements, and therefore opportunities to enhance Value-for-Money, efficiency, effectiveness, sustainability and resilience.

The emergent IP\&MF proposed in this report recognises, and is based on, the following key premises:

- That infrastructure comprises an evolving continuum of interconnected systems which is required to meet changing needs in both time and space, and therefore new infrastructure delivery projects cannot be conceived in isolation from existing legacy infrastructure, from future known infrastructure needs, or from the developing culture and socio-economic policies within which they exist; 
- That the planning, appraisal, design and operation of resilient and sustainable national infrastructure can therefore no longer be managed purely as a collection of individual technical challenges: it is instead a complex and interwoven socio-economic and technical problem;

- That uncertainty about future needs and environments can give rise to opportunity and risks, and that these need to be accommodated in terms of design for adaptability and resilience;

- That realised and latent interdependencies can be a valuable asset that should be continually appraised and developed throughout the planning, appraisal, design and operational life of the related infrastructure. For example, when interdependence is considered holistically then concepts such as infrastructure corridors can be seen to be an economically attractive proposition;

- That there are laws, statutes and varying practical constraints within which infrastructure has to be delivered, including, but not limited to, issues of legacy infrastructure, delivering affordability, working with prior investment (time, money and political capital) in decisions, and the need for resilience in respect of a wide range of socio-economic, ecological and security hazards;

- That effective and efficient governance or more accurately 'stewardship' of infrastructure requires a shift away from an individual asset management perspective, and requires a wide range of institutions and enterprises to collaborate in developing a framework of efficient and effective policies, plans, processes and institutions;

- That there is a need to embed a context-dependent learning process that can inform the development of strategic policy, governance/stewardship and valuation of infrastructure and associated interdependencies on a continual basis in support of investment proposals, such as upgrades, modifications and asset management and maintenance;

- That there are existing and well established infrastructure appraisal processes and practices, and therefore an approach that is complementary is required when proposing an Interdependency Planning \& Management Framework that is, so far as practicable, compatible with existing guidance and professional practice.

- That critical project interdependencies can be very complex, multi-dimensional and dynamic in nature, and therefore not immediately apparent from an analysis of direct linkages between hard infrastructures. Tools that allow this exploration are required to identify the critical complex links between interdependencies and multiple contexts well beyond the traditional project boundaries.

Underpinning this initial version of the IP\&MF is a holistic and systemic view of infrastructure as a network of assets and 'system of systems'. The IP\&MF framework proposed envisages infrastructure assets being continually appraised and developed throughout the proposal, commissioning and the operational life of the infrastructure. It has been generated from principles of systems thinking such as those implicit in the PESTLE analysis framework; it has been informed by existing approaches, methods and tools used in Systems Engineering such as Enterprise Architecture Frameworks (e.g. Ministry of Defence Architecture Framework), Zachman's architectural viewpoints [19], and Lano's N ${ }^{2}$ Charts [20] it has been guided by the lessons from the OMEGA Centre's study into Mega Transport Projects [3 and 4] which are equally applicable to other forms of National Infrastructure Projects; and 
it has been influenced by current thinking on the importance of careful consideration of the 'FrontEnd' of projects [21].

This document reviews the context of the problem, with particular focus on the purpose and nature of infrastructure and the existing guidance on project appraisal within the HM Treasury Green Book. The case for an open systems approach to managing and planning for infrastructure interdependency is presented and this is followed by an outline of the proposed IP\&MF with illustrative applications. Finally, the overall recommendations and areas which could benefit from further refinement are summarised.

\subsection{Infrastructure: Assets and Services}

The purpose of infrastructure is to enable (a) the operation of a modern developed society and (b) the growth and productivity of its economy. First, it meets essential needs of society, supporting services such as the removal of waste, the provision of potable water, supply of heat and power, and provides assets and services required for social interaction and wellbeing. The second aspect, which is inherently linked to the first, is in supporting the productivity and growth of the economy such as the facilitation of work, the transfer and transformation of information, resources and goods, and the production and supply of goods and services, thereby creating value. For example, National Infrastructure is defined by the UK Government as "those facilities, systems, sites and networks necessary for the functioning of the country and the delivery of the essential services upon which daily life in the UK depends" [cited in 22, p8] going on to state that these "networks form the backbone of a modern economy and are a major determinant of growth and productivity." [2, p5]

The definition of infrastructure, and its division in terms of 'hard' physical assets and 'soft' intangible infrastructure [23] is a common one. A further common distinction is between infrastructure which supports societal wellbeing - social infrastructure (e.g. schools, healthcare, and justice) and infrastructure which enables growth and prosperity - economic infrastructure (e.g. example energy and transport). Linked to these are classifications of infrastructure in terms of industrial sectors. This division can be seen in the National Infrastructure Plan [2], which also indicates that it is predominantly concerned with the 'hard' infrastructure. The Centre for the Protection of National Infrastructure [24] and Cabinet Office [22] use a classification of infrastructure in nine industrial sectors, and is of interest as it looks at the 'soft' aspects of infrastructure in addition to the 'hard' engineered assets. 'Soft' infrastructure could equally include the education system, the justice system, welfare, regulations and the financial system. A further example of the classification of infrastructure sectors is found in the UK Infrastructures Timeline report produced by Engineering the Future under the coordination of the Royal Academy of Engineering [14]. As with the National Infrastructure Plan, however, this division into industrial sectors relates to existing and planned infrastructure projects, and as such does not provide a complete systemic definition of infrastructure. In themselves, none of these classification schemes explicitly address the full set of economic and social capabilities enabled by the infrastructure, nor the societal or economic benefits that result. In fact each of these interpretations has been created for a slightly different purpose, and none claim to be exhaustive or for use in this general purpose. All are shown in Table 1mapped alongside each other.

The provision of a working infrastructure system rapidly leads to expectations of continual operation and the benefits that arise. Thus when failures in parts of all this infrastructure occur, they are likely 
to have immediate impact, potentially on a wide range of stakeholders, both directly through the loss of function in one or more assets, and also indirectly from the loss of layers of valuable services that depend upon the satisfactory performance of critical infrastructure assets. The propagation of impacts arising from failures (or successes) can also show considerable temporal variation. Impacts can emerge instantaneously in the case of technical failure, or over longer time periods in the cases of spatial planning failure, or over-use and congestion. Perceptions of acceptable performance levels for complex infrastructure may evolve over time and depend on the criticality of the services they enable, and may not be fully understood until specific failure events occur: hence definitions of resilience may change within the lifetime of an asset, and according to differing social, economic, political and cultural expectations. Such failures in infrastructure, and loss of dependent services, can raise high levels of emotional reaction, including the potential for media controversy and political intolerance. The design of resilient and sustainable infrastructure is therefore a complex sociotechnical problem, and achieving resilience is a process of managing uncertainties, understanding system vulnerabilities, and very importantly, designing for adaptability. For these reasons, it is understandable why infrastructure has tended to be considered as discrete types (e.g. electricity networks separate from gas, water, sewerage) but also now why, with so much infrastructure already existing, it is important to develop a holistic appraisal framework encompassing the broadest range of social, as well as technical, modes of failure and success.

The increased availability of data and use of information provides an important additional layer to infrastructure development and use. It is being increasingly used to inform infrastructure design, to support urgent operational decisions, and also to shape and inform the decisions of infrastructure users. For example, new technologies in communications and information management such as mobile phones coupled with the application of 'cloud-based' software services provide opportunities for new modes of interaction between users and infrastructure, and example applications can be seen in providing real-time road traffic and train performance information so reducing traffic congestion and carbon emissions in transport systems, and in emergency management such as issuing weather warnings (e.g. floods and storms). It also points to the critical importance of information and communications systems. 
Table 1 - Infrastructure Sectors ${ }^{4}$

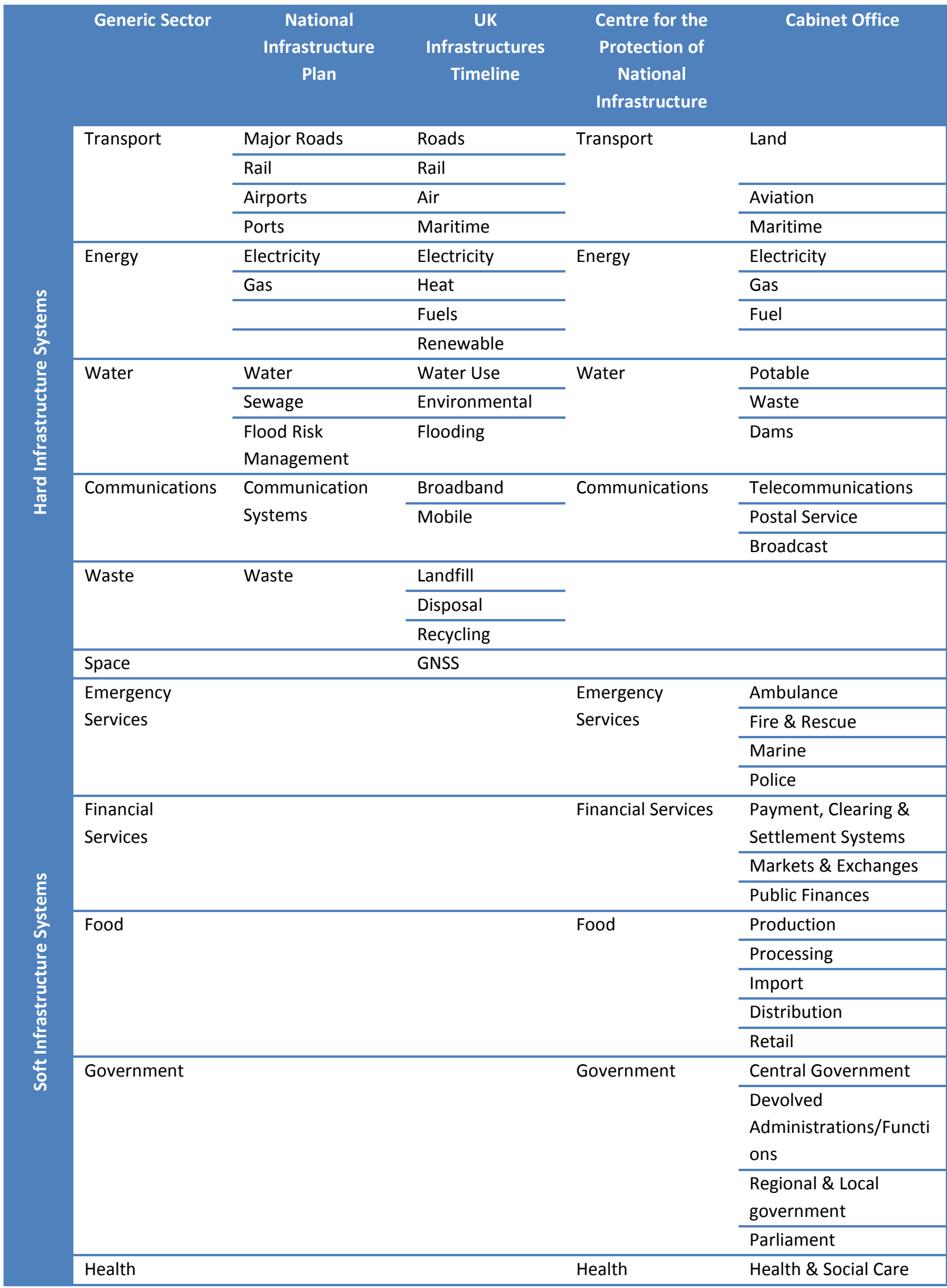

${ }^{4}$ These classification schemes do not include, for example, education. It can be argued that all of these schemas are in various ways incomplete and could usefully be extended. 
When developing the IP\&MF, and to ensure that the resulting framework is generally applicable, the concept of infrastructure has been defined in the broadest possible form, comprising a network of both 'hard' physical assets and 'soft' systems, with the layers of 'soft' services utilising the network of 'hard' systems to fulfil their functional purpose. A combination of the categorisation schemes introduced in Table 1 has been therefore been used. This incorporates both the soft and hard systems perspectives, with a more detailed breakdown of the hard infrastructure assets by industrial sector as provisionally identified in Table 2. A more complete taxonomy of infrastructure interdependency has been developed by Carhart and Rosenberg [18].

Table 2 - Preliminary Infrastructure Sectors for Proposed Framework

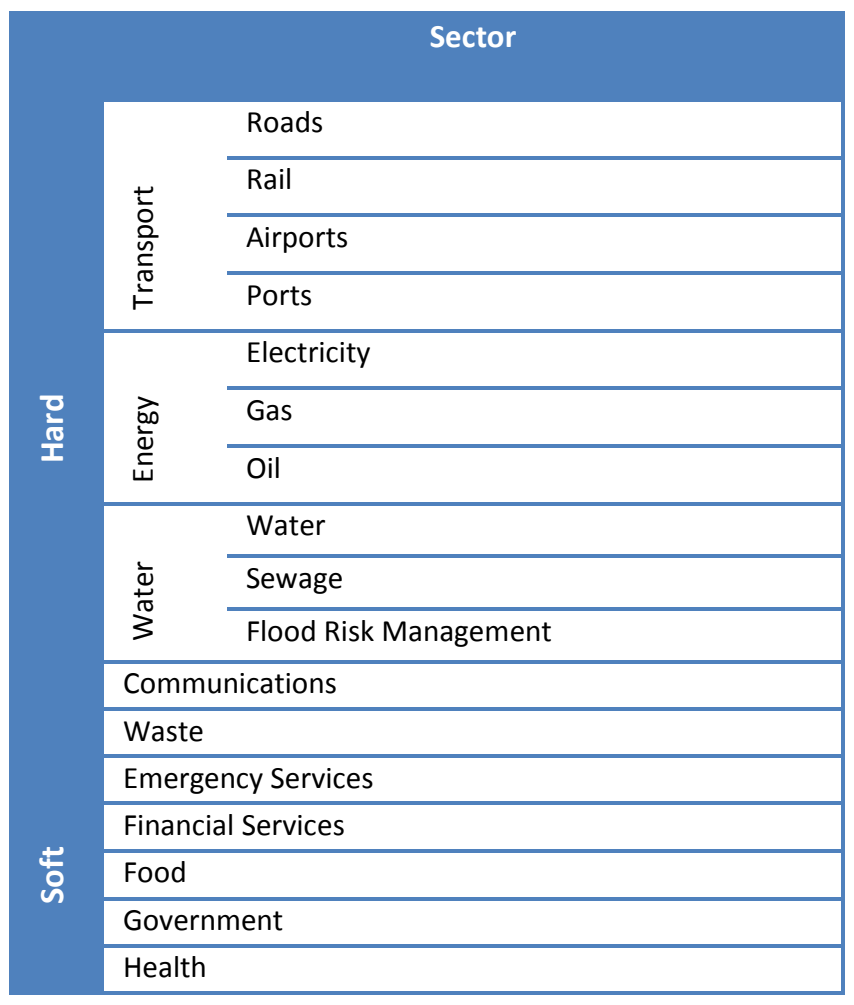




\section{Foundations of the Research}

This section provides additional details on the underpinning foundations for this research and the development of the Interdependency Planning and Management Framework. It begins by exploring the value of identifying, planning and managing interdependency within the infrastructure context It outlines the systems approach and why viewing infrastructure as a 'system of systems' may be beneficial for the planning and management of infrastructure interdependencies. It sets out the case for an open systems approach to infrastructure projects, drawing on the lessons learnt from a study of thirty large-scale infrastructure developments. The importance of establishing the purpose of an infrastructure project is also discussed along with the need for a holistic, long-term, whole-lifecycle view of infrastructure and its concomitant value.

\subsection{Systems Approach}

The systems approach offers a means to address and move forward from the current fragmented approach to infrastructure and infrastructure projects. There are many definitions of what constitutes the 'systems approach' but all remain consistent in essence. One of the earliest definitions [25] described the systems approach as a reaction to problems which are not well suited to the classic analytical approach in which the interactions between parts are neglected and the behaviour of the whole system is thought to be a linear sum of the behaviour of those parts.

The systems view holds that the whole system cannot be fully understood from the study of its parts in isolation (particularly in isolation from the system's operational context); the whole system poses properties, generally by way of the interactions between the parts, which are not present in the parts individually.

The developing view of infrastructure discussed above seems to suggest that infrastructure systems have interactions between their component parts that cannot be neglected and the properties of the whole system are not necessarily well served from analysis of those same component parts. It would therefore follow that the systems approach is a suitable candidate to assist in the analysis of infrastructure as a system.

The systems approach provides a way to improve the understanding of the behaviour of the whole system. Through systems modelling tools it may be possible to characterise and quantify the way in which the elements (or component parts) of the system interact, and from this, to understand the overall system's response.

The systems approach also pays particular attention to the impact of stakeholder needs and capability requirements on understanding the purpose of the system.

When investigating a system it is natural to draw a boundary around that system and its stakeholders so as to constrain the investigation and make it more manageable. Once the boundary has been drawn there is a tendency to focus on the parts, requirements, and interactions within that boundary and limit or neglect entirely the interactions across the boundary. This is a 'closed system' approach. While this can make the task easier, neglecting the transfers and interactions across the boundary can be detrimental to the system in question as well as important systems outside of the boundary. Simple systems tend to have a clear boundary with somewhat limited and predictable cross-boundary interactions, but complex systems can rarely be constrained in this way. Problems can also arise if the 
boundary is placed inappropriately for the challenges at hand. This tends to happen when the purpose of the system is not properly understood (and there may not be a consensus over the purpose of the system), or if the problem is constrained too early in the project. Defining the problem and the boundary too soon in the project can limit the innovation of a solution.

The figure below (Figure 1) is taken from a report on the role of Systems Engineering in $21^{\text {st }}$ Century Infrastructure [26]. At the bottom it depicts the 'hard' economic infrastructure system described in the previous Section as being comprised of a number of interacting systems, each concerned with a different infrastructure sector. Hence the Energy sector manages the interacting components (assets, services, resources etc.) which make up the Energy System. The Energy System interacts with the Transport, ICT, Water and Waste Systems. This enables activities within the 'soft' social infrastructure system which reciprocally require aspects of the economic infrastructure system. The social infrastructure is in turn relied upon by society in general, the activities of which are enabled by it. This diagram represents the view of infrastructure as a complex system of systems. It is clear that a boundary could be drawn in any number of ways, yet many complex interactions and interdependencies will exist across those boundaries that are important to the operation of the elements within the boundary and to society as a whole.

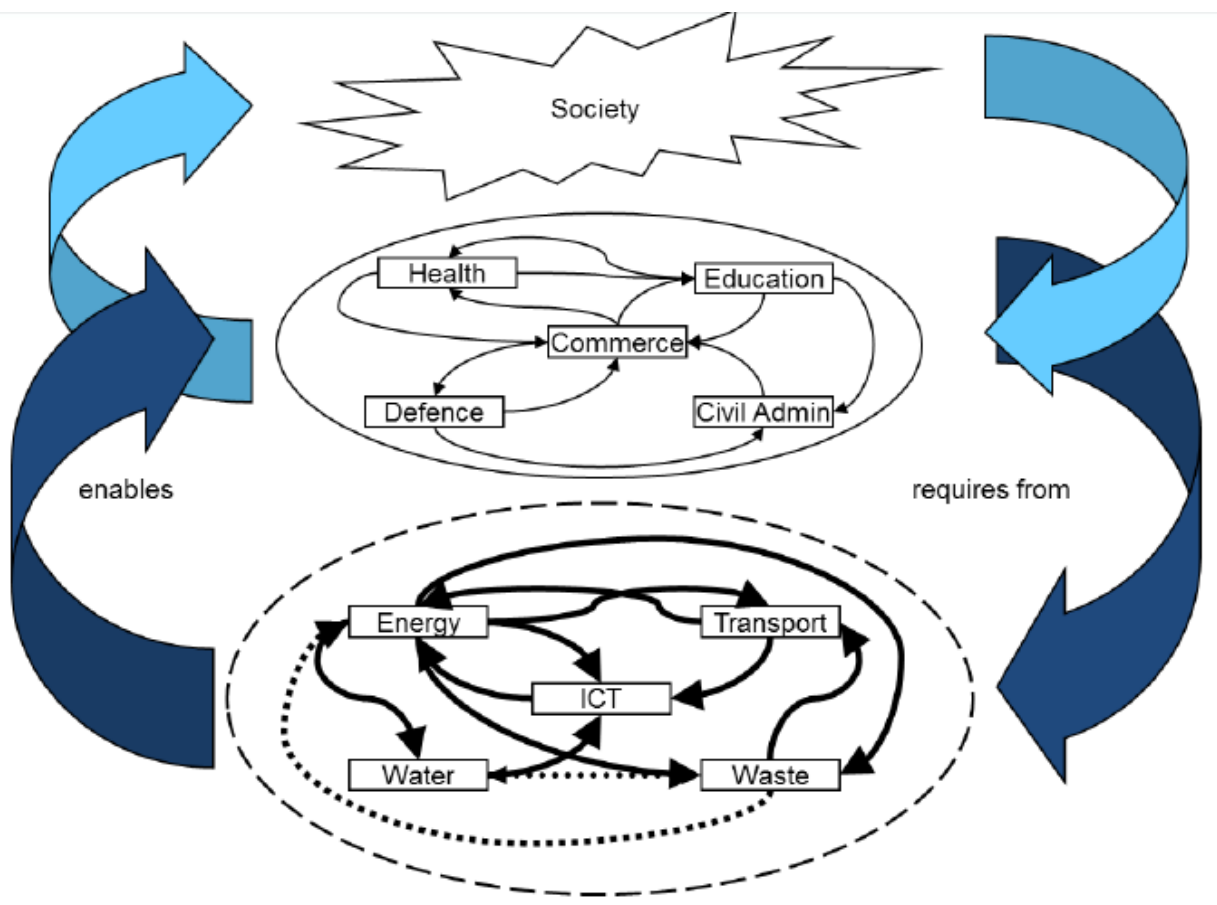

Figure 1 - An Infrastructure System of Systems

Further evidence for the pressing need for such an approach to be embedded within the management of infrastructure projects can be seen from the study of Mega Transport Projects described below.

\subsection{OMEGA Lessons}

Researchers at the OMEGA centre (UCL) have conducted a detailed study of thirty large-scale infrastructure developments in the transport sector. Amongst the lessons drawn from analysis of these Mega Transport Projects (MTPs) [27] is evidence which supports an open systems-based approach to infrastructure development, and this comprises one important component in the case for adopting the systems approach to infrastructure development. 
First, researchers found that large-scale infrastructure is often developed within a complex programme of 'mega projects' delivered over time and in different contexts. These programmes or 'meta projects' (the term used by the OMEGA Centre) frequently become critical 'agents of change' with multiple spatial, economic, environmental and other implications, including the transformation of the context into which they are placed: as such they comprise a wicked planning problem characterised by incomplete, contradictory and changing requirements to which there is no obvious and assured solution. In addition, the researchers found that such 'agent of change' functions in the UK are often evolutionary in nature, emerging from piecemeal developments over long periods of time, this being the result of a lack of clear strategic policy. A key requirement, beyond conventional planning approaches, is therefore seen as a need to allow for unanticipated outcomes as part of an 'emergent order'.

Many of the OMEGA case study projects interviewees suggested that a singular lack of attention was paid to the 'agent of change' potential of MUTPs, often resulting in a series of 'lost opportunities' for the positive exploitation of project interdependencies. This reflects the rather narrow framing of such MUTPs solely as providers of transport infrastructure - as was the case for Hong Kong's The Western Harbour Crossing, The Randstadrail and Beneluxlijn in the Netherlands, The UK's Jubilee Line Extension (JLE) and Athens Metro for example - without due attention being paid to their potential capability to directly or indirectly stimulate urban regeneration and wider spatial and sectoral change. Conversely, projects such as the Hong Kong Airport Express, Tokyo's Metropolitan Expressway and Oedo Line, Sydney Cross City Tunnel and the UK's Channel Tunnel Rail Link (CTRL) were inherently positioned as components of broader agent of change strategies (albeit with varying degrees of success and bearing in mind that agent of change objectives were not always a part of the initial raison d'etre of the project - as was the case for New York's Air Train and the CTRL).

The OMEGA research identifies context awareness as a key factor in successful decision-making throughout the whole infrastructure lifecycle. The recognition and analysis of the impacts and the implications of the complexities, uncertainties, risks and opportunities associated with a changing context (temporal, geographical, cultural, environmental, political, policy, societal and economic) is a fundamental requirement. Changes in context inevitably impact on the purpose and function of infrastructure and also its interdependencies. . For example The Attiki Odos (Athens ring road) failed to monitor critical contexts surrounding social and environmental sustainability of the project. This led to a successful court injunction by an influential stakeholder group to change the route, the reactive nature of the intervention would have certainly led to increased costs and delays to the project. The Sydney Cross City Tunnel failed to adequately monitor social contextual forces regarding key stakeholder groups leading to much dis-satisfaction in the final project. Elsewhere, interviewees suggested that there were few (if any) examples where formal monitoring systems were established.

Opportunities can therefore arise during the project lifecycle to seek enhancement of infrastructure, its attendant plans and programmes and related interdependencies. Researchers at the OMEGA centre argue that there is a benefit in using such 'time-to-breathe' periods to review the purpose of infrastructure developments and use these ideally as opportunities for beneficial changes in the infrastructure planning and design objectives. From this, we conclude that any project interdependency planning and management framework should encompass a periodic sensitivity analysis of the context of an infrastructure development, and this may lead to a need to adjust project objectives, appraisal methods/approaches and delivery plans and programmes. Other work 
conducted in the area of project management at UCL supports this viewpoint and extends the traditionally execution-oriented view of 'project management' to be the more strategic and context aware viewpoint of projects now referred to as the 'Management of Projects'. The above conclusions are substantiated by the findings of the analysis of the project timelines and key decision-points of the numerous case studies in the OMEGA research programme which, among other things, highlight the influence on political decisions and policy agenda changes that lead to changes in previous positions at pivotal stages of project developments which in turn lead to 'add-on' /expanded aims for the project or a scaling-down of these aims. Examples of such experiences may be noted in the case of the JLE, where the last minute de-specification of the line to meet government demands for a service to the millennium dome has ultimately led to large upgrade cost. The Netherland's HSL Zuid could not deliver the specified safety system in a timely manner, which had a significant negative impact on its programme.

The Tokyo Oedo Line and Yamate Tunnel projects, both of which were mothballed for several decades due to funding and environmental issues respectively and also Greece's Rion-Antirion Bridge which was the result of many decades of planning could be seen as examples of Serendipity and seizing the moment: the two Japanese projects enabled novel solutions to be developed and constructed which would not have been previously possible, whilst the Rion-Antirion bridge in Greece profited from both the development of technological expertise in modelling seismic risk and availability of funding at the right time. In a similar way Athens which had suffered decades of pollution and transport crisis seized the opportunity to use EU funding to resolve these issues.

A key lesson drawn from the OMEGA Centre's research programme is that proposed infrastructure projects (limited to transport in their study) are intrinsically part of many existing social, cultural, economic and political systems(as shown in Figure 1) and thus understanding how these systems will affect and be affected by such new projects is essential. This multi-contextualisation is in alignment with an 'open systems' approach to infrastructure planning. Using this paradigm can address not only issues, problems and influences that occur within the infrastructure development project (endogenous interactions), but would also permit consideration of the complex interrelationships between the infrastructure assets and the external socio-economic and natural environment in which they have been placed (exogenous interactions). Infrastructure development is thus seen as a more 'organic' phenomena in which there are emerging risks and opportunities generated by the external turbulent environment, and hence a need for on-going 'stewardship' (or 'governance') to guide investment and planning in infrastructure over the longer term.

OMEGA research programme findings suggest that the MUTPs that are treated as 'closed systems': cannot be properly appraised as a constituent of the wider (and more complex) context into which they are placed. In doing this they face the reality of having their potential positive impacts seriously underestimated and, among other things, frequently exclude legitimate stakeholder involvement in decision-making. Evidence of this among the OMEGA case studies was noted in the New York Airtrain, which was not fully integrated within the surrounding public transport network, and the Tokyo Metropolitan Expressway, an example of a closed system which was forced to become more 'open' by context due to pressure from local residents demanding a more environmentally sensitive design solution. Another example of closed to open projects include the French Millau Viaduct which moved from "a closed system to an open one under influence of two main movements: the increasing public sensitivity to sustainable issues; globalisation, in particular through the impact of EU regulation on the 
trend to open the competition. The Perth to Mandurah Railway was planned as a closed and carefully bounded system which, following best practice contracting in Australia, was carefully protected from outside interference and scope creep.

The Athens Metro, was a project where major changes (such as relocating Kerameikos station to avoid an ancient cemetery) were introduced during the construction period for cultural and archaeological reasons with considerable added cost implications. Another example of introducing changes during the construction phase is the JLE where the new objective to complete the project by the opening date of the Millennium Dome contributed to significant cost escalations.

In contrast, the current infrastructure planning, appraisal and delivery paradigm the most common criteria employed for judging a project's 'success' are the 'iron triangle' criteria of delivering projects on time, on budget, and within prescribed specifications. This can be seen as a highly mechanistic approach focused on the execution phase where things are built. However, the emphasis on delivering projects within budget, within schedule and to specification presumes that these estimates and specifications were accurate and reflected what the project was set to deliver. The London 2012 Olympic and Paralympic Games demonstrated how critical it was to fully understand the scope of the project and its critical objectives before sensible estimates of budget could be set for appropriately specified assets. Although there was a great deal of media interest in the London 2012 budget as it rose from that originally bid to final estimate, it was precisely because of this extremely careful and thorough evaluation and analysis that the full composition of what comprised London 2012 was understood. This focus, known to many in the industrial projects sector as Front End Loading (FEL), has been proven to be highly beneficial for successful project outcomes

The changing demands placed on infrastructure systems make judging success and failure more problematic, and it requires a rigorous and complete project framing in order to enable all subsequent monitoring and appraisal to be based upon a well-defined and transparent baseline business case. From a whole system's viewpoint, the original purpose used to establish the project, and the contextual influences that prevailed at the time, provides a fundamental benchmark for assessing success since this defines the need for the project and is the basis from which all planning and specification is derived. For example The CTRL and New York's Airtrain were treated more as a commodity than a service during the latter planning and construction phases. However the original aims of both projects, to provide highly efficient transport links, evolved into a project focused on supporting regeneration and development.

OMEGA researchers also found that a clear and shared understanding of what comprises 'sustainability' and 'sustainable development' is frequently lacking in infrastructure developments and poses a number of critical challenges. These include questions about whether such projects can effectively meet the needs of intra and inter-generational equity of sustainable social, economic and environmental development - including international concerns about energy consumption, carbon footprints, climate change, greenhouse gases and $\mathrm{CO}_{2}$ emissions. Furthermore, there is frequently an inbuilt conflict between minimising environmental impact and the manner in which many infrastructure developments are designed and funded, and this undermines the degree to which infrastructure could potentially contribute successfully towards achieving high-level policy objectives. It is also apparent that stakeholders have differing perceptions of what constitutes a 'successful' project, and that these evolve over time. 
Drawing from these OMEGA survey returns, it was concluded that by and large the UK has an undeveloped set of methodologies for valuing sustainable development outcomes of MUTPs, whereas, in cases in France and Japan (for example) OMEGA research findings suggests that Sustainable Development Visions (SDVs) require long-term appraisal and evaluation cycles that need to be supported by sustained political support and institutional frameworks which share in the same vision. It is questionable, it is contended, whether SDVs can expect to be delivered in the absence of such institutions.

The work presented by the OMEGA centre therefore recognises that the changing demands and expectations, including in the area of sustainability, presents a challenge when seeking to establish a holistic view of project success and failure. It makes a case for appraising infrastructure developments transparently in a manner that lays out all key financial and non-financial costs and benefits within a policy-led multi-criteria framework; the aim being to assist in setting priorities and making trade-offs between project objectives and stakeholder interests much clearer. From this we conclude that defining infrastructure developments and their attendant interdependencies in terms of narrowly framed monetary costs and benefits, would unduly constrain infrastructure planning, appraisal and design stages from identifying a fuller set of project interdependencies and the potential for their successful exploitation.

The work of the OMEGA Centre also highlights the importance of effective and early engagement with key stakeholders is seen as critical in infrastructure specification, planning, appraisal and delivery, a perspective reinforced by UCL's Management of Projects mode of considering projects. Critically, this implies an 'opening up' of the infrastructure planning and design process to a plurality of new stakeholders so as to identify a broader set of potential risks and opportunities, and avoid the premature discarding of options. Frequent scans of the stakeholder environment are recommended in order to assess the willingness, ability and capacity of different stakeholder groups and networks to exert critical influence on pivotal decisions. It is seen as giving important opportunities to manage risk, uncertainty and complexity, and therefore in the context of this work to explore, more widely than at present, the potential for beneficial and unfavourable interdependencies. Importantly, early consideration of these differing viewpoints allows the project to be scoped and specified appropriately from the outset.

Examples of effective consultation among the MUTPs reviewed for the OMEGA research programme include the Perth-Mandurah Railway and two projects for which new consultation processes were established in response to initial public opposition - the TGV Med in France and the Boston Big Dig. Examples of poor consultation include the Greek Rion-Antirion Bridge and Attiki Odos, both of which prompted several appeals to the Supreme Administrative Court. In regard to the Oresund Link between Sweden and Denmark it is suggested that stakeholder involvement/resistance contributed to a thorough environmental assessment and stringent environmental requirements.

The final area researched by the OMEGA Centre is the importance of the softer factors in areas such as governance, regulation and policy frameworks, institutions and organisational learning, and the effects these have in determining the likely success of infrastructure development programmes. For example, they found that infrastructure development is unlikely to be able to deliver the full range of change benefits, unless it is accompanied by suitable and permanent institutional, policy and legislative frameworks throughout the project lifecycle. The degree to which individual statutory 
processes represent an obstacle or a positive benefit will, it should be acknowledged, largely be dependent upon the context in which they are situated. Thus, in Greece (for example), the statutory and institutional framework for MUTPs is seen to be problematic in not being capable to control development pressures generated by them. Conversely, statutory processes were positively beneficial in producing rapid and defensible decisions for some projects, as in the case of the JLE and CTRL. OMEGA research findings also suggest that, irrespective of context, political and other decisionmaking processes can create conditions which are favourable to a particular type of MUTP as in the case of the private sector funded project in Hong Kong such as the Western Harbour Crossing.

They also note that systematic, widespread lesson-learning and sharing is not currently a significant feature of infrastructure specification, planning, appraisal and delivery and that there are few examples in the public domain of post-project evaluation that go beyond time/cost/specification assessments of project performance. Furthermore, they report evidence to suggest that knowledge acquired by the private sector in the field of MTP development is frequently guarded for commercially competitive gain, often ultimately at the expense of the public purse. They argue for the systematic sharing of 'good practices' and key lessons learned through 'knowledge sharing platforms'.

The factors identified by the OMEGA Centre research have bearing at all the key levels of policy, organisation, programme and project. At the policy and organisational levels they point to: a) the importance of a collective approach to the governance of infrastructure in a mixed market economy with the goal of breaking the tendency for institutions to retreat into silo-based thinking; $b$ ) the need for a 'stewardship' role to set planning policies and investment priorities, and accept and respond to turbulence in socio-economic and natural environments; and c) the means to support organisations in recognising and developing their capacity to successfully create and manage interdependencies. At the programme and project levels there is a need to develop a systematic approach to interdependency management that: a) is capable of helping decision-makers cope with wicked planning problems that have open system boundaries; b) provides the drive needed to identify and engage with a broad range of stakeholders and thereby create the potential for innovative new design options encompassing interdependency; c) provides a means of tracking the success or failure of infrastructure developments, proposed and implemented, against a broad set of measures of performance with the scope to accommodate both complex and conflicting success criteria; and d) the capacity to work with existing economic appraisal approaches including monetised and nonmonetised multi-criteria approaches.

\subsection{Conclusion to Foundations of Research Approach}

Some strategies commonly associated with project management can create barriers to the identification, planning and management of interdependencies. These include:

- Removing the system of concern from its context within whole system of systems;

- Narrow enquiry of stakeholder needs;

- Defining an inappropriate system boundary;

- Adopting a closed system view; and

- Defining a narrow purpose.

These behaviours can overly constrain the development of innovative solutions. Each of these actions tends to encourage a 'jump to a solution' by narrowing the options. These actions can be problematic in terms of developing an efficient and effective solution. 
As a complement to the classic approach, the open systems approach has many tools and methods to offer which may assist in removing the barriers to the consideration of the risks and benefits of interdependency between infrastructure systems. The framework outlined in the following section advocates such an approach, and attempts to embody systems theory and the lessons learnt from the previous Mega Transport Project case studies as a foundation. 


\section{A Proposed Framework for Infrastructure Interdependency Planning \& Management}

Building on the challenges described in Section 2 and the lessons set out in Section 2, this section outlines a framework for the planning and management of infrastructure interdependencies. This requires the adoption of some key underlying principles including a move towards the stewardship of infrastructure across a dynamic and evolving continuum and the integration of the framework throughout the project lifecycle, but particularly in the early strategic stages.

\subsection{Delivering Stewardship of the Network of Infrastructure Assets}

A key principle of the interdependency planning approach set out in his report is that effective and efficient strategic governance or 'stewardship' of infrastructure requires a shift away from an individual and myopic asset management perspective. This move to a principle of stewardship requires a wide range of institutions and enterprises to collaborate in developing a coherent framework of policies, plans, processes and institutions to guide infrastructure investment and planning against some long-term vision. The stewardship role set out in the IP\&MF will have a critical impact in determining how infrastructure interdependencies will be framed and assessed during the project appraisal process, and in promoting the collaborative approach needed to identify beneficial interdependencies across Government, regulators and industrial sectors. The proposed IP\&MF would require Government to:

1. Oversee the integration of infrastructure development over the long term, within a framework that balances current socio-economic and fiscal needs with longer term ecological sustainability and asset value;

2. Define planning policies and investment priorities which are sufficiently flexible and responsive to changes in technologies, socio-economic policy and the natural environments;

3. Support local and national government departments, regulators and commercial enterprises in developing their capacity to create and manage interdependencies successfully.

\subsection{The Role of Project Management in the Consideration of Interdependencies for Infrastructure Projects}

Delivering infrastructure projects successfully has never been easy and as the challenges and issues presented by the modern world increase, so it is also likely that the expectations of the projects themselves increase. This places significant pressure on those charged with managing these projects and history records that whilst successes such as the London 2012 Olympic and Paralympic Games proves that such success is possible, it remains the case that other projects will not be guaranteed such success. This concern is now recognised in the UK government by establishing the Major Projects Authority ${ }^{5}$ (MPA). Amongst the MPA's objectives and responsibilities is one that is highly relevant to the consideration of interdependencies:

\footnotetext{
"The MPA is supported by a clear and enforceable mandate and has the authority to:.... make a starting gate review, or equivalent, mandatory for all new projects/programmes to assess deliverability before project delivery gets underway."
}

\footnotetext{
${ }^{5}$ https://www.gov.uk/government/policy-teams/major-projects-authority
} 
The reference to a 'starting gate review' is illustrative of an increasing emphasis on the very early stages of the project lifecycle, referred to as the 'initiation' phase [28] or the 'front-end' of the project [29]. This phase of the project is being focused on by both academics and practitioners as there is significant evidence from previous projects that problems with the projects at the latter stages of delivery and transition into operation can be traced back to problems and issues that occurred much earlier in the project lifecycle [30 to 32]. From this body of work it is demonstrated that there is a need for clear and solid leadership, governance and management of this early stage. This is not straightforward as the early stage of a project's lifecycle is where there is very little firm information, much speculation, and the potential for many sources of influence and decision-making. This current research project on interdependencies potentially adds to this complexity as the consideration of possible interdependencies at the project's front-end could lead to not only changes in scope of the project, but also how it is fundamentally considered and understood. This was illustrated with the HS2 case where the Parliamentary Bill needed to allow the first phase was originally conceived as being a Transport Bill, but after consideration of the potential for 'dark fibre' was submitted to parliament as a Hybrid Bill. Similarly, whilst the Northern Line Extension (as discussed in the following section) is clearly understood as a transport project, it is motivated by the need for social and economic regeneration of a part of south London.

In the context of this research project, two important issues have emerged that relate to the progression of the project through its lifecycle and the attributes and competences of the manager of the project. The first is that the credible seeking of potential interdependencies has to involve a range of parties who would be expected to have a possible interest in the project. The identification of these stakeholders and the prior consideration of what their interests would be is a task that needs to be undertaken both in the correct way and at the right time. The IP\&MF proposed here has identified two opportunities at different points in the project lifecycle to seek and discuss possible interdependencies.

The first, and most important of these two opportunities, is very early on in the project, when the project can be understood and described in principle but without any firm decisions having been made about it. In systems engineering it would be when the problem or issue that is seeking a project solution is understood and is still being explored, and before any single solution is decided upon. In the context of this project, HS2 phase 2 most closely fitted this categorisation with much still being debated about the project, and with the A14 being at the opposite end of this project development spectrum as the A14 widening project was very clear in what it was to be and the focus had moved to consider how it would be funded.

After this first 'golden' opportunity to seek interdependencies has passed, the project will move through stages that refine and elaborate, and as part of this will enter into the formal statutory submission for permission to proceed. As part of this process projects will be considered by those who are recognised to be potentially affected by the project, typically involving neighbours, utility providers, and others with pertinent jurisdictions or proximities. This statutory consultation period is often driven by considerations of disrupted impact or need for interface working, so often identifies negative interdependencies. However, if a second multi-party interdependency exercise were to be arranged towards the end of this consultation period (prior to final statutory approvals) then there is the potential for positive interdependencies to emerge. An example of this is given below [33]: 
"The Ravensbourne, at Brookmill Park, downstream of Lewisham [south London] used to flow through a concrete flood channel and provided negligible environmental or social value. The extension of the Docklands Light Railway (DLR) to Lewisham provided the perfect opportunity to restore this section of river. This is because the flood channel actually provided the most direct route for the DLR to Lewisham and using it would have minimal environmental and visual impact on the park and surrounding area. The Ravensbourne could then be diverted into a new natural channel in the park to create a quality river environment for both wildlife and people to enjoy. This scheme was financed by DLR Ltd., CGL Rail and LRG Contractors as part of the planning conditions for the DLR extension."

Having identified the points in the project lifecycle where the search for interdependencies can be conducted, it is also important to consider the implications of such additional activities on the project manager.

Project managers are specialists (whether considered as individual or organisations) and increasingly operate on a quasi-professional level, with membership organisations, formalised bodies of both practitioner and academic knowledge, and internationally recognised practitioner qualifications. However, project management as specialist area is not a traditional profession with chartered status and formalised licences to practice as would be found in areas such as architecture and engineering. Thus project management can be considered to range from those that operate fully professionally, complying with all codes of conduct and demonstrating awareness of advanced knowledge and practice, through to those with limited knowledge, skills and experience of what it takes to manage projects. For the majority of practicing project managers there are some 'givens' that have emerged over time. An example of this is the mantra that will often be heard of what project management is it's about the delivery of the project to time (schedule), to cost (budget), quality (scope and specification). This is telling as it raises two very important points for this research on the seeking of interdependencies. The first is that it puts the project manager in charge of the delivery of the project only - it is focussed on the execution phase of the project. Second, and directly related, it begs the question of who is it (if it isn't the project manager) who sets these essential parameters and constraints? This area is one that the academic Peter Morris has been writing about since the late 1980s and indeed his concern was such that he distinguished between 'project management (execution focused) with 'The Management of Projects' which is both more strategic and holistic. Why is there the need for this distinction? The answer is that the early stages of a project (pre formal sanction to proceed) are most simply described as vague, complex and messy. Unlike the latter stages of a project where there is clarity of what the project is, how much it will cost and how long it will take are all calculated, the early stage of the project's front-end are where ideas abound, fundamental options arise (.e.g. abandon, delay, accelerate, fundamentally alter) and where power and influence can come from many sources, including politics at all levels and high status individuals and organisations. The best of project managers embrace these challenges and work on the project from the outset. To do so, they need a very different skillset from the execution orientated project manager. They will need skills associated with diplomacy, politics, strategic visioning, leadership, estimating, team building and communication. Critically, they must accept that projects in the early stages of their life will change. It is this last aspect that the proactive search for interdependencies will involve as by definition, if interdependencies are found they should be expected to change the project parameters 
- potentially fundamentally. There is thus a potential tension as a balance is sought between making progress and not seeking to rush into a 'locked in' project solution too early.

The London 2012 Olympic and Paralympic Games demonstrated how careful and thoughtful project management can deliver outstanding success. The time critical nature of the project led to a reverse engineering approach from the opening date backwards, and this went completely through what the project comprised and what was expected of the organisations involved in it. The lessons from London 2012 will continue to emerge as other major infrastructure dependent events draw on the experience and learning arising, but these lessons are not limited to genre specific projects, but for all major and complex projects.

There is recognition in the project management community of both the need for and difficulty in gathering lessons that can be usefully learned for future projects. Whilst 'lesson learned' sessions may be timetabled on many projects, it is clear that many problems persist and project managers are prone to refer to 'reinventing the wheel'. Thus, to recommend adding the need to learn from the experience of seeking interdependencies to this difficult post project exercise is not a guarantee that it will be beneficial. However, such a recommendation is made and it is also arguably within the remit of the Major Project Authority to not just stipulate this, but to work with others such as those involved in the London 2012 Games to find the most effective and engaging ways to draw these lessons out and ensure they are used subsequently.

It is vital that those in positions to influence and direct the future of project management recognise this need to move project management into the early stages of the project lifecycle. The players involved are those such as the project management organisations, bodies such as the Major Projects Authority and academic and similar institutions and organisations that deliver project management education and training.

Having considered the possible implications to those involved in leading and managing the early stages of a major and complex project, it is necessary to outline the process that is proposed to commence seeking interdependencies.

\subsection{The Interdependency Planning and Management Process}

Figure 2 and Figure 3 depict an overview of the Interdependency Planning and Management Framework (IP\&MF) illustrating the three main activities of 1) Problem Structuring; 2) Measurement and Appraisal; and 3) Creating Stakeholder Understanding. All activities are undertaken iteratively and in some cases concurrently, and are informed by an evolving and maturing knowledge base in Interdependency Planning and Management.

Figure 4 below illustrates the fundamental elements of the proposed IP\&MF, and the process map in Figure 5 shows how this could be made operational and integrated with the Green Book's ROAMEF life-cycle. The following sub-sections describe in more detail the steps set out in the process map looking in turn at each of the three activities.

Figure 6 defines how this process was implemented for the test cases set out in the following chapter and describes the particular methods and tools used. It also indicates how the framework could integrate with MCA tools (see also Appendix B). 




Figure 2 - An Overview of the Interdependency Planning and Management Framework

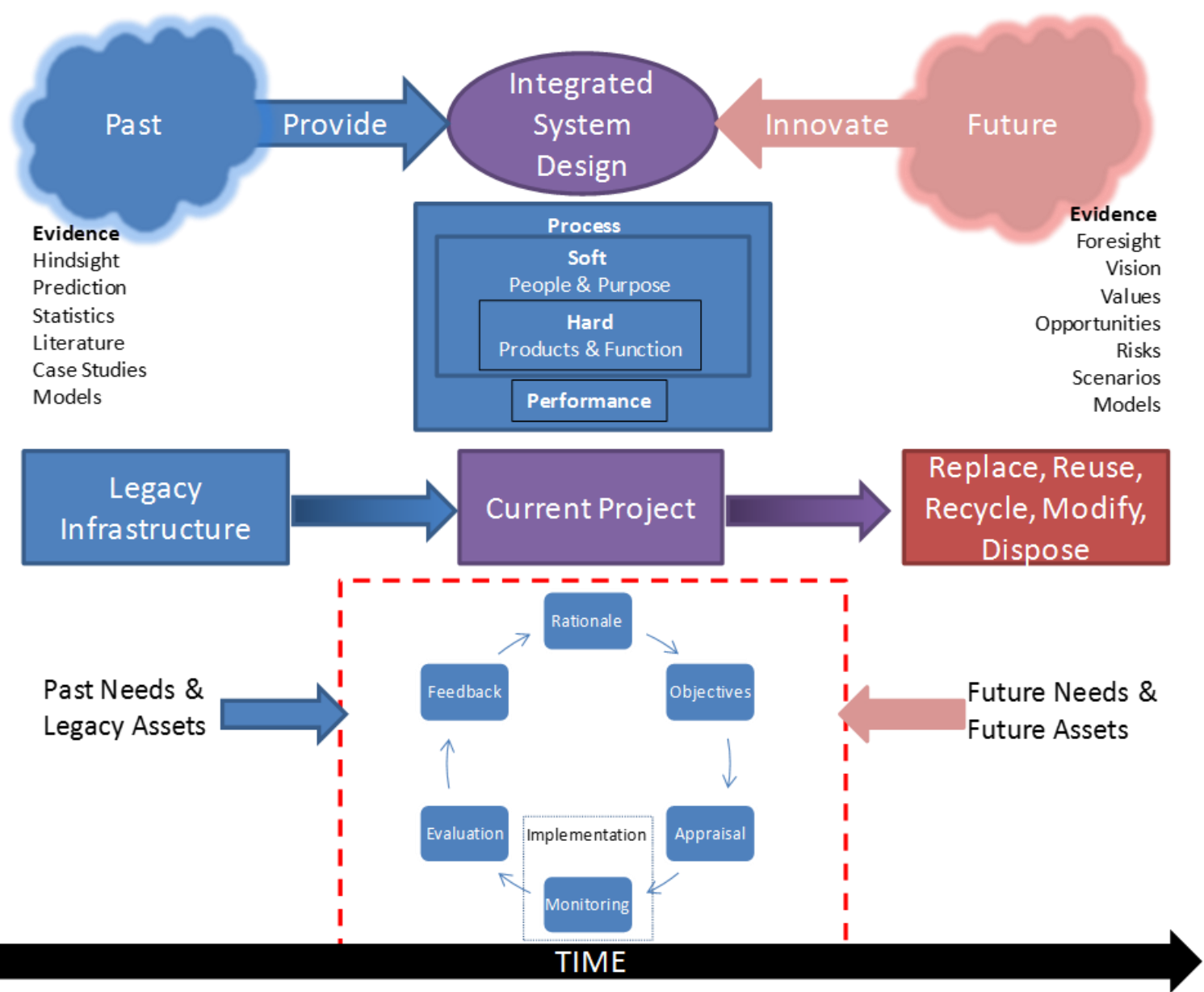

Figure 3 - Schematic of interdependency Planning and Management Framework 


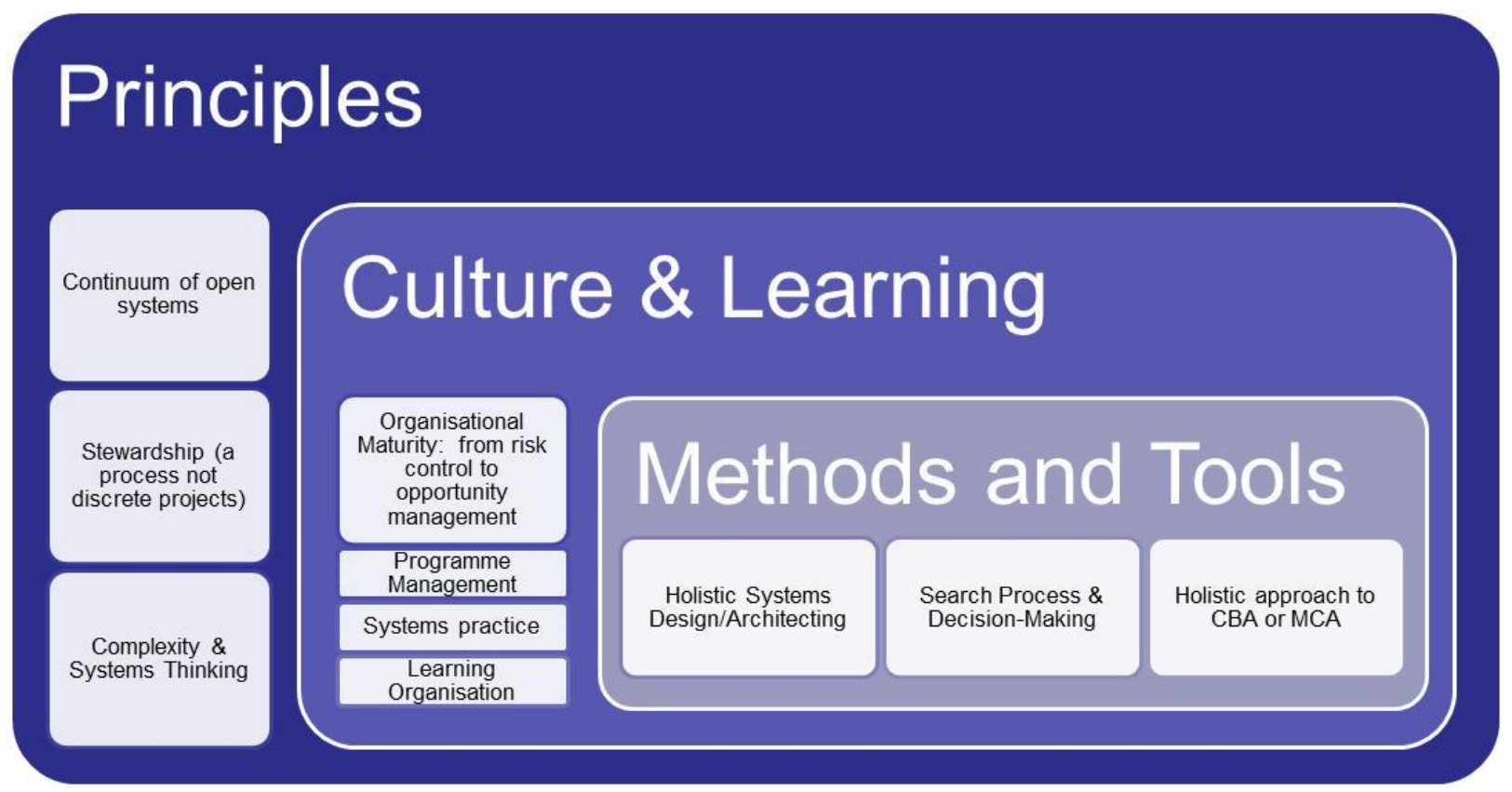

Figure 4 - Fundamental Elements of the IP\&MF

\subsection{Problem Structuring Activities}

The Problem Structuring Activities can be broadly described by eight sub-activities detailed below.

\section{Explore System Boundary and Policy Context}

The IP\&MF recognises that infrastructure comprises a network, or 'system of systems', developed and upgraded iteratively over the lifetime of the infrastructure in response to the currently perceived stakeholder needs as depicted in Figure 5. This first activity is a preliminary step cementing the approach's recommendation that policy makers, economists, planners and engineers adopt three principles in particular:

1. That infrastructure development requires a holistic, open systems view of infrastructure, and in this regard to recognise and adopt a 'system of systems' perspective.

2. That all 'hard' infrastructure systems are developed within a framework of 'soft' systems comprising policies, processes and practices, coupled with the institutions, organisations and people that define and implement them.

3. To question and explore the accepted and/or perceived system boundary for an infrastructure development in order to engage with a wider range of stakeholders and create the potential for innovative project scoping and design options.

The following sections identify the steps needed when establishing the context to a proposed infrastructure development in order to be able to identify potential interdependencies. It comprises the outward looking parts of problem structuring process. 


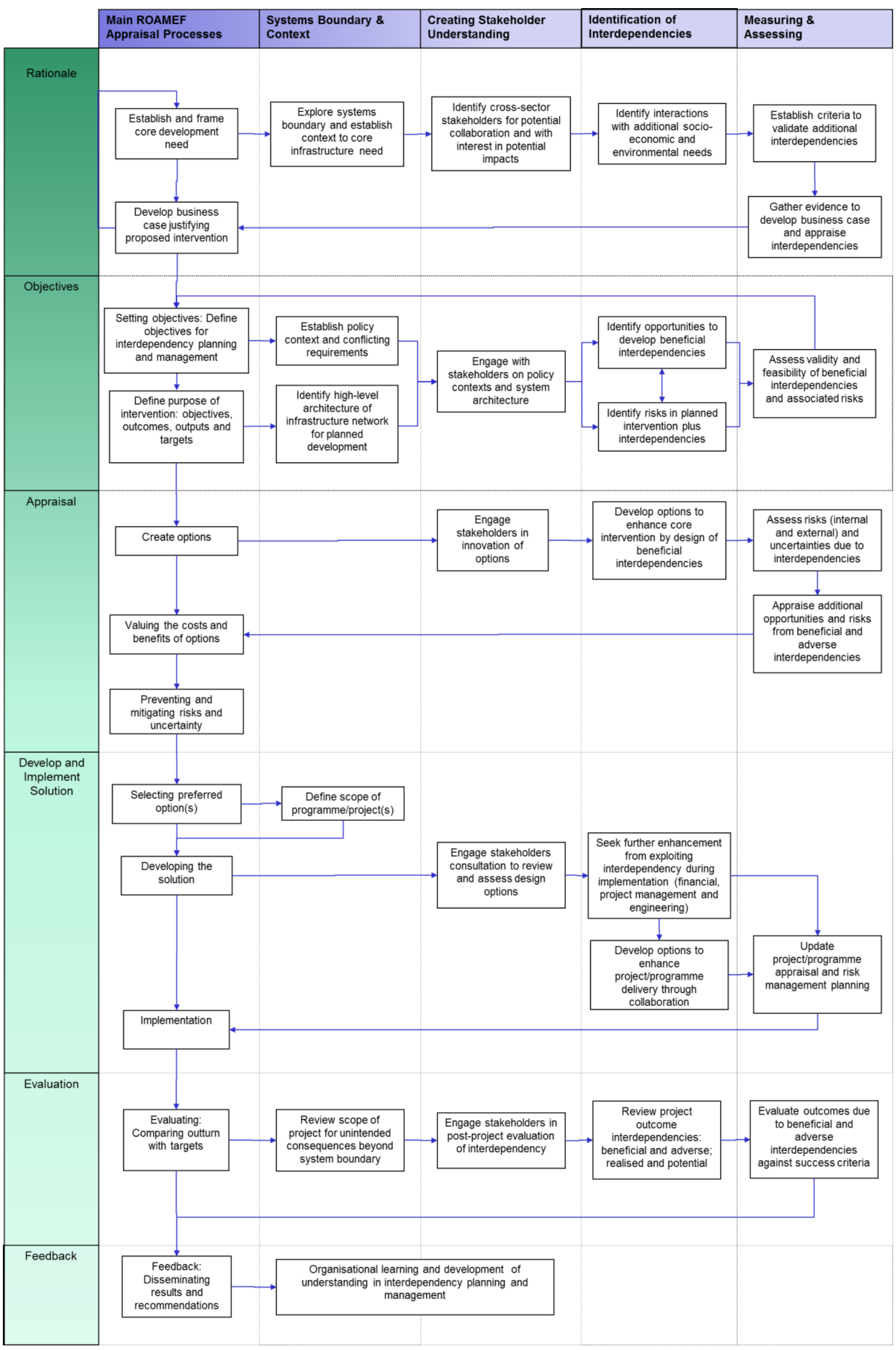

Figure 5 - IP\&MF Process integrated with the Green Book ROAMEF Cycle 


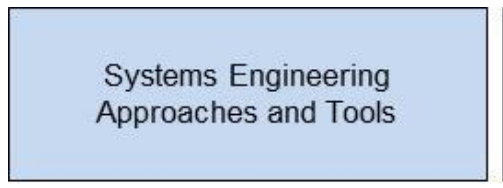

Planning PESTLE and MCA Toolset

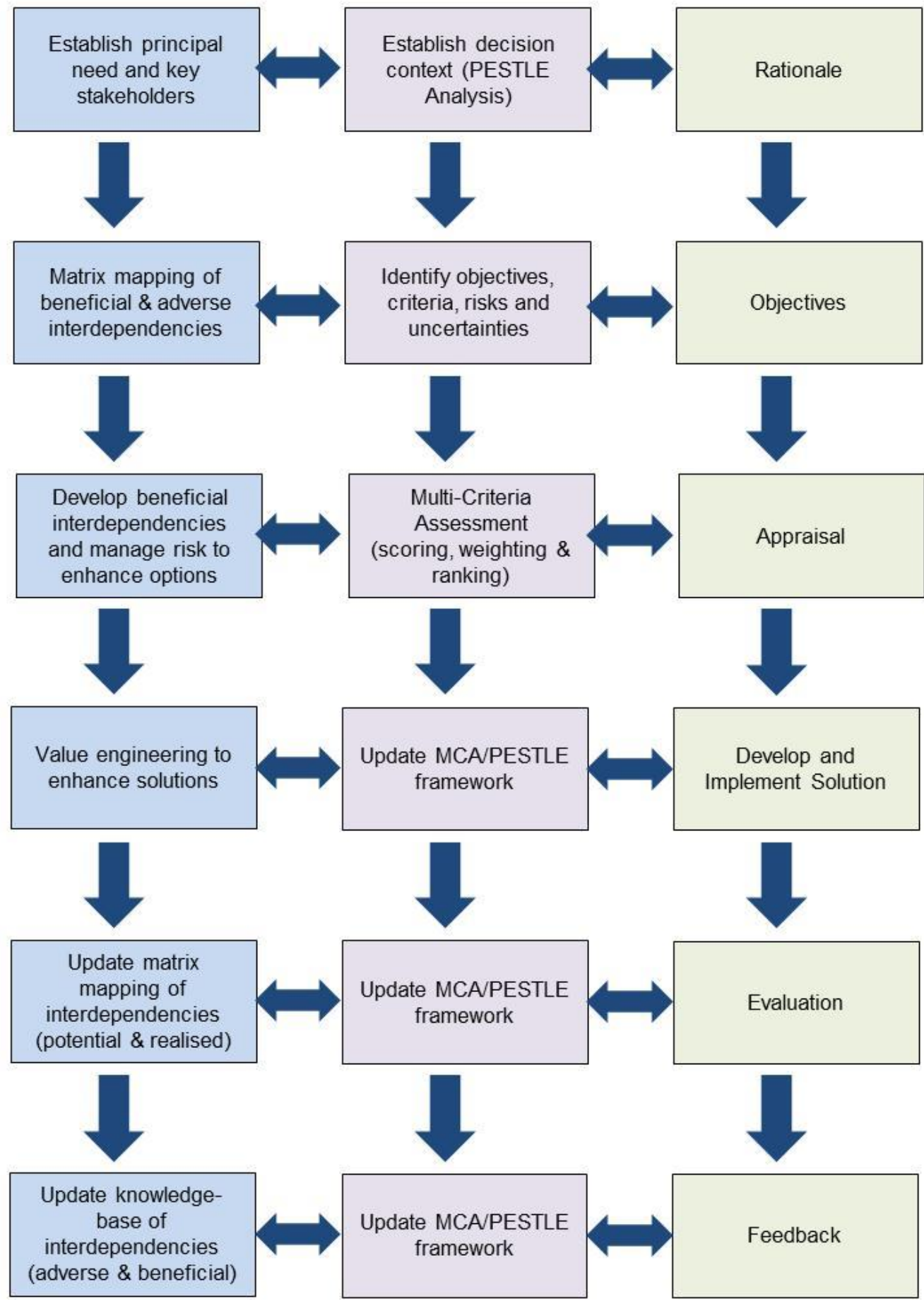

Figure 6 - IP\&MF Case Study Implementation Process 


\section{Establish and Frame Core Development Need}

Establishing and framing the core need for an intervention represents the first actual step in the IP\&MF process (see Figure 5). In the vast majority of cases an infrastructure development will be initiated in response to a 'core need'. This may be stimulated by any one, or a mix, of:

1. socio-economic changes, e.g. changing patterns of work, demographic change, developments in policy and regulation;

2. the development of new technology and a desire to benefit from associated benefits;

3. to respond to perceived problems with the performance of existing infrastructure, e.g. the renewal of ageing infrastructure assets which no longer meet the societal demand or expectations;

4. a lack of resilience, for example due to climate variability, changing security threats, or due to increased socio-economic dependence on a given asset base.

The process of identifying beneficial interdependencies requires, a priori, a definition of the core needs for which a prospective infrastructure development is to be proposed. This step is necessary to ensure that criteria of success for the core development goal can be established, and therefore that the cumulative effects of beneficial and adverse interdependencies can be appropriately framed and assessed in the appraisal process.

For example, where the core need for an infrastructure project is identified as 'enhancing economic development opportunities through transport improvements', then this will inevitably require additional infrastructure and policy developments beyond the core scope of increasing transport capacity. In such a case, the opportunity to plan the exploitation of beneficial interdependencies in support of the core need would be opened up significantly, and might comprise the development of a shared infrastructure corridor so as to increase the capacity of other utilities servicing the defined economic development areas. In such a case, the planning and appraisal of beneficial interdependencies should be more easily aligned with, and supportive of, the core infrastructure development goals.

For a scenario in which the core need is identified in terms of a narrower scope, i.e. 'increasing public transport capacity', the transport route may nevertheless be capable of fulfilling the function of a shared corridor for additional utilities. However any such beneficial interdependencies identified from a high-level planning perspective, may at the discrete transport project level, be perceived as incidental to the goal of meeting the core transport need, and furthermore, may be assessed as decreasing the resilience of the core transport system, e.g. a burst water main might potentially risk closing a railway line or road.

\section{Explore Boundary and Context to Infrastructure Need}

The successful planning and managing of interdependency, whether seeking to enhance beneficial interdependencies (opportunities) or minimise adverse interdependencies (risks), will necessitate a creative and systematic search to reveal relationships between the defined need for the core intervention and other socio-economic needs and policy goals which comprise the 'context'. This initiates a process of identifying potential stakeholders and seeking opportunities to collaborate beyond scope of a traditional infrastructure development project. 
The aim of this stage is to reveal needs in other industrial sectors and socio-economic and environmental policies that have either the potential to conflict or compliment the proposed infrastructure development and establish a shared understanding of the decision context (technical, administrative, political, social, and environmental structures that surround the decision being made). It is important to consider the objectives of the decision making body, the administrative and historical context, the set of people who will be affected by the decision and an identification of those responsible for the decision.

Systems thinking approaches are used to identify and apply a structure to complex situations, and to develop, represent and communicate understanding in support of decision-making.

"Systems thinking is a discipline for seeing the 'structure' that underlies complex situations" [34]

Achieving a better understanding of needs and the policy context at the project outset will support the following objective setting stage. The application of system thinking approaches at this stage in the IP\&MF should ensure that:

1. Sufficient time and resources are applied to explore and reveal the stated and implied needs driving the core development, and that these have been adequately understood, tested and defined before specific technologies are selected and solutions are considered.

2. The context for the core infrastructure development is defined, including the framework of relevant socio-economic and environmental policies and regulations, and likely interactions with the network of other infrastructure whether through physical, social or informational connectivity.

3. Uncertainties are identified with respect to the context to the project and the core needs. This represents a first step in the risk management process.

4. The needs of other relevant infrastructure sectors are identified and related to the core project needs. From this, opportunities for cross-sector collaboration and risk sharing may be identified and likely project stakeholders identified.

When setting objectives and establishing the purpose of the intervention, further detail will be acquired defining the policy context:

1. Conflicting policy requirements will need to be identified;

2. Negative interactions with the network of other infrastructure and services should be explored, including impacts on infrastructure resilience;

3. Uncertainties in the context to the proposed infrastructure development should be established and assessed.

A range of planning and systems engineering toolsets are suitable for application in this stage of the process, including use case analysis, scenario planning, stakeholder analysis, multi-criteria assessment (MCA), uncertainty management techniques, impact assessment and sustainability appraisal frameworks. 


\section{Identify Architecture of Infrastructure Network}

A systems architecture provides a high-level, conceptual model that depicts the structure or layout of a given system, and the interactions it has with other hard and soft systems in a network. This step should capture and represent the planned development and its relationships with other infrastructure. It is an essential step in communicating the general nature of the infrastructure development with stakeholders, and provides a platform for identifying interdependencies.

When implementing the IP\&MF, the important principle derived from Zachman's work [19] is that multiple stakeholder perspectives are necessary if a rich understanding of the relevant infrastructure (existing or planned) is to be formed, whilst the identification of which key stakeholder views are important and will depend on the specific context.

Systems architecting may involve a range of modelling techniques, including for example spatial maps of potential routes; matrices depicting known interactions with other infrastructure systems and policy goals; system dynamics models and influence diagrams; process mapping; and network modelling techniques.

\section{Identify Interactions with Additional Socio-economic and Environmental Needs}

Identifying beneficial interdependencies at an early 'business case' stage in the ROAMEF cycle makes it more feasible to align and incorporate them with the core project needs. Similarly the early identification of uncertainties and adverse interdependencies early on in the project life-cycle will facilitate more effective and efficient risk management and project decision-making: beneficial and adverse interdependencies will be identified before the project becomes substantially set, and before political, financial and legal commitments become firmly established.

This stage in the interdependency planning and management process requires the engagement of key stakeholders in the identification of:

1. Shared needs, including opportunities for collaboration throughout the lifecycle of the infrastructure development programme, beneficial integration of infrastructure assets and services, as well as seeking alternative approaches to delivering services and meeting policy goals;

2. The additional needs of other sectors which could potentially be met during the delivery and operation of the proposed core infrastructure development. Examples might include provisioning to meet future needs of future infrastructure projects, or developing plans to share space as exemplified by shared infrastructure corridors [35].

The outcome from this step in the development of the problem structuring and modelling activities initiated during the previous stages. These should adequately capture and describe a set of positive (beneficial) and negative (adverse) interdependencies comprising opportunities and risks for consideration as part of the business case and in the planning, engineering design and appraisal processes.

The examples presented as test cases (Section 5) illustrate how this stage of the IP\&MF could be implemented using the systems matrix mapping, PESTLE sustainability appraisal and MCA tools (Appendix B Integrating Multi-Criteria Analysis.) 


\section{Identify Opportunities to Develop Beneficial Interdependencies}

Opportunities to develop beneficial interdependencies may arise at any stage during infrastructure development. However the following four key stages are identified when an active search for interdependency may enhance infrastructure performance. The first two represent intervention in the strategic 'front end' phase, identified above as being the most important point of intervention. The third stage for potential intervention was described above as having a reduced opportunity for significant impact as the purpose and boundary become more fixed. Application of the framework during the fourth stage would demonstrate a maturing of the framework and the mind-set required for its application:

1. Whilst defining the needs for the infrastructure (see above);

2. When setting the objectives and appraising an infrastructure development project;

3. During the implementation of infrastructure when alternative more effective or efficient design options may be identified;

4. Post-project when options to retrofit or upgrade an infrastructure asset may yield social, environmental or economic benefits.

When developing highly innovative and complex projects, planners and engineers face fresh challenges, and in such cases technical knowledge learnt from previous projects may not be directly applicable. Systems engineering approaches provide a means of being able to move from innovative conceptual designs to real-world solutions more rapidly, and achieve this in complex environments. For example, in both case studies for the High Speed 2 Phase 2 workshop [10] and the Engineering the Future workshop [13] a matrix mapping approach was used whereby the principal elements of the infrastructure system, the policy context and physical environment, are placed along the leading diagonal. The off-diagonal boxes were then used to capture and model the interdependencies between the principal systems set out on the leading diagonal. This approach helps to organise and guide a search for interdependencies in a systematic manner. Other tools could be used to support this step in the process, including network models, system dynamics modelling, and hierarchical systems models [18].

The identification of beneficial interdependencies will rely on a creative process and benefit from prior interdependency management practice and knowledge. Standard types of knowledge will be required to help identify and develop a shared understanding of the interdependencies for a given infrastructure development project, and these will generally include knowledge of methodology, domain, context and use. Knowledge and creative ideas may be captured using a range of standard qualitative research methods including workshops, interviewing, brainstorming, and through public and other consultation processes. Interdependencies may also be revealed from review of documented knowledge and systems modelling approaches as noted above. Example case histories and learning from related experience, together with the cultural openness to explore interdependencies with stakeholders will support this activity.

There may be a reluctance to engage in the identification and development of beneficial interdependencies, particularly when the majority of benefits are external to the key stakeholders and proponents of the core infrastructure development. It is in this space that the stewardship role is required, in particular to audit the quality of the process followed when identifying and developing beneficial interdependencies. This should: a) ensure that all appropriate knowledge areas and types 
have been considered; b) review the inclusiveness of stakeholder engagement; and c) ensure that no significant barriers to the implementation if the IP\&MF exist.

Interdependencies between a proposed infrastructure development and other networked infrastructure systems and policies need to be categorised in a robust and systematic way. The categorisation scheme, outlined in Table 3 has been developed with reference to the work of Rinaldi et al.[36], Ventura et al.[37], the National Infrastructure Plan[2] and the report by Frontier Economics[5], and is further extended in the paper by Carhart and Rosenberg [18]. The first four characteristics relate to the ways in which the elements are related. The last three explicitly classify the type of failure which might occur as a result of the interaction (which might be implicit from the first four characteristics). Some of these characteristics relate to the specifics of a relationship or dependency between two systems, while others relate to co-dependencies on a third element (such as common cause failure or sharing the same physical location).

\section{Identify Risks from Adverse Interdependencies}

The risks from adverse interdependencies should be identified throughout the planning, design, implementation and operation of the infrastructure, and it is particularly beneficial to apply them early on before project goals have been substantially set. For example, an infrastructure project that requires embankments to be built in a catchment has the potential to exacerbate existing flooding problems, but alternatively with careful design, may be able to improve flood protection.

A wide range of risk and uncertainty management tools are available to capture, report and manage the negative effects of adverse interdependencies. Table 3 includes a description of negative interdependencies within its classification.

\section{Define Objectives for Interdependency Planning and Management}

In addition to the standard ROAMEF procedures for setting objectives, the IP\&MF calls for a planning and appraisal of options (and sub-options) based around the identified interdependencies, i.e. this should include:

1. Negative interdependencies arising from the interaction between the core proposed infrastructure development and the network of all other infrastructure systems. These would be assessed for their total adverse impact on the resilience of the whole network of critical infrastructure.

2. The additional beneficial interdependencies which could be developed where these are judged as being achievable, worthwhile enhancements to the proposed infrastructure development.

At this stage, it will be necessary to decide which beneficial interdependencies should be incorporated within the scope of the core infrastructure development project and include these within the business case and public consultation. This decision will be based on the evidence presented via the appraisal process, including information provided by a MCA, CBA and risk and uncertainty management tools. It will need to ensure that additional (auxiliary) engineered interdependencies do not undermine or diminish goals of core infrastructure development. 


\section{Table 3 - Interdependency Characteristics}

\begin{tabular}{|c|c|}
\hline Interdependency Characteristic & Description \\
\hline $\begin{array}{l}\text { Physical } \\
\text { Interdependency/Dependency }\end{array}$ & $\begin{array}{l}\text { - A transfer of resources, the output of one element becomes the input to } \\
\text { another. This could be further refined to capture the nature of the } \\
\text { transfer (e.g. P1 = Transfer of people). } \\
\text { - A shared physical dependency between the two elements on a third } \\
\text { resource (i.e. both elements consume the same fuel or use the same } \\
\text { trained staff) }\end{array}$ \\
\hline $\begin{array}{l}\text { Digital } \\
\text { Interdependency/Dependency }\end{array}$ & $\begin{array}{l}\text { - A cyber transfer of information. Again this could be refined to capture } \\
\text { additional detail of the transfer. } \\
\text { - A shared dependency between the two elements on the transfer of } \\
\text { information from a third party source. }\end{array}$ \\
\hline $\begin{array}{l}\text { Geographic } \\
\text { Interdependency/Dependency }\end{array}$ & $\begin{array}{l}\text { - The elements are located in the same place, or within close proximity. } \\
\text { - The row and column are irrelevant, the connection here is mutual. }\end{array}$ \\
\hline $\begin{array}{l}\text { Organisational } \\
\text { Interdependency/Dependency }\end{array}$ & $\begin{array}{l}\text { - The elements are linked through a financial or logical mechanism with a } \\
\text { transfer from the row to the column. } \\
\text { - The elements are organisationally linked by shared ownership, shared } \\
\text { governance, or shared oversight. } \\
\text { - The elements are mutually dependent on the services provided by a } \\
\text { third party organisation }\end{array}$ \\
\hline Cascade Failure & $\begin{array}{l}\text { - The disruption of one system causes the disruption of another (in the } \\
\text { corresponding matrix column). }\end{array}$ \\
\hline Common Cause Failure & - The elements share a common failure cause. \\
\hline Escalating Failure & $\begin{array}{l}\text { - The failure in one element has an effect on an existing condition or } \\
\text { recovery from failure in another element. In some respects this is an } \\
\text { implicit emergent property of the existence of bi-directional cascade } \\
\text { failures between two elements. }\end{array}$ \\
\hline
\end{tabular}

\subsection{Creating Stakeholder Understanding}

\section{Identify Cross-Sector Stakeholders for Potential Collaboration}

Effective and early engagement with key stakeholders is seen as critical in infrastructure specification, planning, appraisal and delivery as a means of identifying a more comprehensive and robust set of the beneficial and adverse interdependencies. Early consideration of these differing viewpoints allows the project to be scoped and specified appropriately from the outset, rather than be bedevilled with downstream major changes. It also discourages the premature adoption of solutions dominated by one specific viewpoint (e.g. a technology) as well as helping to avoid the premature discarding of options.

Critically, stakeholder engagement supports the 'opening up' of the infrastructure planning and design process to a plurality of stakeholders. It provides an important process for gathering knowledge from a range of domains and industrial sectors, as well as eliciting location specific knowledge. The greatest benefits for interdependency planning will accrue when there is broad participation from across relevant industry sectors and from the input of cross-disciplinary knowledge.

Obtaining this knowledge is of interest through several different stages of the process. Frequent scans of the stakeholder environment are recommended in order to assess the willingness, ability and capacity of different stakeholder groups and networks to participate in, and influence, decisionmaking. 
At this stage in the interdisciplinary planning and management process, the purpose of engaging with stakeholders is to:

1. Develop a greater understanding of the context to proposed infrastructure development and the policy environment (as described in the previous section);

2. Make best use of the available multi-disciplinary knowledge;

3. Promote widespread participation in innovative thinking across industrial sectors;

4. Reveal both shared, complementary needs and conflicting needs and requirements of infrastructure users, providers and operators.

The outcome of this step in the IP\&MF is an analysis of stakeholders and their potential interest in the interdependency planning and management process for the core infrastructure development project. The success of all stakeholder engagement activities (set out in this section and below) should be judged by the degree to which it encourages and facilitates the input of knowledge and innovative thinking from a broad group of stakeholders in an open and inclusive way, e.g.:

1. In providing sufficient encouragement for interested third parties to propose auxiliary options and collaborative ventures such that innovative ideas are advanced and considered on merit, even where these may be perceived as beyond formal scope of the core project and/or the primary interests of the project sponsor;

2. In identifying more rapid and lower risk deployment of new technology and/or cost savings through collaboration;

3. In securing the interest and ideas from a broader community of stakeholders than would be the case with a single-sector, 'silo-based ' consultation;

4. In countering constrained or biased thinking, vested interests in proprietary technologies, and undue deference to orthodoxy and perceived authority.

\section{Development of Interdependency Planning and Management Practice}

The IP\&MF recognises that there is a need to embed a context-dependent learning process that can inform the development of strategic policy, governance/stewardship and valuation of infrastructure and associated interdependencies on a continual basis. The purpose of this learning and feedback process is to support future investment proposals, such as upgrades, modifications and asset management and maintenance, and inform policy development.

The success of initiatives to implement and develop interdependency planning and management practices will depend on the behaviours and knowledge built up in the infrastructure policy, planning and engineering communities. Already reports such as that prepared by Frontier Economics [5] provide examples of the benefits (realised and potential) from interdependency management.

During the post-project evaluation stage it is recommended that generic learning is abstracted and made available to support other infrastructure development projects. The review of the project outcome should engage stakeholders in the post-project evaluation of interdependency for the following steps:

1. Review the scope of the project to establish unintended consequences and interactions not identified during the infrastructure planning, appraisal and engineering design;

2. Evaluate the benefits realised from the identified positive interdependencies

3. Monitor and assess the risks from adverse interdependencies. 


\subsection{Measurement and Appraisal}

\section{Establish Criteria to Validate Interdependencies}

Beneficial interdependencies, may be expressed as shared needs early on in the ROAMEF cycle, then collaborative objectives and additional desired outcomes, and finally in terms of additional design options as solutions are proposed. At all stages it will be necessary to assess the performance of options in support of decision making. Criteria and sub criteria are the measures of performance by which the alternative options, and sub-options, may be objectively judged.

The criteria must be operational and a number of procedures may be followed to arrive at workable criteria. Examples may include 'brainstorming session' involving key decision makers, and possibly other stakeholders. Another approach may be to examine policy statements and secondary information sources from the various interest groups and to derive criteria to reflect their concerns.

"A large proportion of the value added by a formal MCA process derives from establishing a soundly based set of criteria against which to judge the options" [38]

Before finalising the criteria the provisional set of criteria must be assessed against a range of qualities:

1. Completeness - are all important criteria included?

2. Redundancy - are there unnecessary criteria?

3. Balance - is the set of criteria sufficiently well-balanced to cover all issues?

4. Operational - can each option be judged against each criterion?

5. Mutual independence - preferences associated with the consequences of options are independent of each other from one criterion to the next

6. Double Counting - it is quite easy for some basic impact to be recorded more than once in a performance matrix

7. Size - it is important to avoid an excessive number of criteria

8. Impacts occurring over time - attention should be drawn to time differential impacts

Once criteria are derived it is desirable to group them into a series of sets which related to separate and distinguishable components of the overall objective of the decision. Grouping criteria is an important part of the process, helping to check the relevance of the criteria, ease the process of calculating criteria weights and facilitates the emergence of higher level views of the issues, especially regarding trade-offs between key objectives.

Early on in interdependency planning, it will be beneficial to sift and eliminate unachievable options to avoid nugatory data collection effort for clearly impracticable propositions. The value of the beneficial interdependencies should be assessed and validated, and a MCA is recommended for this step. A range of holistic sustainability appraisal tools have been developed, generally based around PESTLE and other sustainability checklist approaches, and these provide a useful means of identifying suitable appraisal criteria.

Similarly criteria for assessing the adverse impacts from negative interdependencies will need to be established at this stage in the process, for example defining the levels of probability and impact commonly used in probability-impact approaches to risk assessment. 


\section{Gather Evidence and Appraise Interdependencies}

Evidence to support the appraisal of interdependencies will be compiled throughout the stages of 1) exploring the systems boundary and context, 2) the creation of stakeholder understanding and 3) during the identification of positive and negative interdependencies. The approach to appraising interdependencies should be consistent with the overall appraisal process for the main project, and holistic sustainability appraisal tools, MCA, and uncertainty management tools can be used to support an appraisal process for interdependencies.

The evidence gathering should support decision making, particularly associated with the business case, the setting of objectives, and the selection of preferred options (and sub-options). Of importance in the management of interdependencies is that there is sufficient evidence firstly to determine whether or not to proceed with the implementation of alternative options derived from beneficial interdependencies; and secondly that the adverse consequences of negative interdependencies have been sufficiently well-defined to assess impacts on critical infrastructure resilience (i.e. beyond the proposed development).

Given the complexity and novelty of many infrastructure projects, and the novelty of seeking to plan and manage for interdependency, the evidence gathering process has to go beyond identifying evidence of what has been done in the past, and instead meet the challenge of what can we achieve dependably in the future. This can be approached using uncertainty management approaches and tools such as interval probability theory (Italian Flags) and others identified in the Blackett Review of High Impact Low Probability Risks [39].

\section{Review Business Case against Maturity of Interdependency Management}

For successful planning and management of infrastructure interdependencies, it is important that the core business case for a proposed infrastructure development should be reviewed to ensure the following conditions have been satisfied:

- That the core need and purpose for the infrastructure development is well-defined and justified, and that this has been communicated to key stakeholders.

- That the context and policy environment to the proposed infrastructure development has been established.

- That a sufficiently broad group of relevant stakeholders has been engaged in a process of identifying opportunities to develop beneficial interdependencies as well as the risks from adverse interdependencies.

- That an objective assessment of the risks and opportunities presented by the negative and positive interdependencies has been included in the business case. 


\section{Interdependency Planning and Management Framework Testing}

The IP\&MF was applied to four case studies during its development life-cycle, and for each example application, it was used to identify, model and investigate potential interdependencies. These test cases were used to demonstrate the suitability of the IP\&MF for application to real-life infrastructure developments, while also seeking to provide a benefit to the actual projects.

The first case study concerned Phase 2 of the proposed High Speed 2 rail network, from Birmingham to Manchester and Leeds. In looking for additional interdependency opportunities, this application of the framework also sought to investigate the holistic evaluation of interdependencies, and the practical workshop-based application of the framework [10].

The second case study investigated interdependencies concerning the proposed Lower Thames Crossing [11]. As well as identifying important interdependencies, it also investigated tools for applying the framework and developed the workshop-based application through the use of individual stakeholder workbooks.

The third case study looked at the Northern Line Extension [11] with particular focus on the policy context, both in terms of the interdependencies involved in the project, and the way in which this is handled by the framework

In addition to these case studies, elements of the framework were also applied in a workshop to investigate the interdependencies between policies and projects identified in Engineering the Future's Infrastructure Timelines [13].

These four example applications are described below in the context of applying and developing the framework.

\subsection{High Speed 2 Phase 2}

\section{Background}

The lack of capacity on the UK's railway network is a significant issue for economic development. Demand for rail travel is increasing, yet the network has remained largely unchanged since it was first engineered. The High Speed 2 (HS2) rail project is intended to help meet the transport demands of a modern economy by improving links between several major urban areas.

The first phase of HS2 is intended to run between London and Birmingham, the second phase extends this to Manchester and Leeds. The government has already identified its preferred route for phase one and taken this to wider consultation. The same process is now being applied to Phase Two. The preferred routes of western and eastern legs have been identified and will be made available for consultation.

This case study explores the opportunities and advantages presented by viewing the HS2 Phase Two project as an element within a wider system of networks. The aim of this case study is to identify a shortlist of potentially beneficial inter- and intra-sector interdependencies with the planned HS2 Phase Two project in order to support the Department for Transport in scoping the upcoming consultation. 


\section{Method}

This case study was conducted through two workshops. The first was held on the $14^{\text {th }}$ of March 2013 and consisted of a brief tutorial followed by three interactive sessions. The workshop consisted of participants from four different infrastructure sectors: Energy, ICT, Water and Transport. The participants represented a broad set of stakeholders with interest in the project, as well as it potential interventions and impacts. The workshop provided a means to engage with the stakeholders and explore the context and boundaries in an open-systems manner. It provided access to the broad policy context across multiple infrastructure sectors.

For the first session the participants were split into four groups based on the infrastructure sectors they represented. A matrix-based approach was used to structure the identification of interdependencies and engage stakeholders in considering innovative options to enhance the core project proposals. The second session provided an opportunity for each group to share their findings with all of the workshop participants. For the final session the groups were asked to identify evidence for and against the further consideration of the identified interdependencies, finally concluding in a broad valuation. This process considered the political, environmental, social, technological and economic value of the interdependency.

The output of this workshop was collated and distributed to the workshop participants. They were asked to consider any additional evidence for a subsequent workshop held on the $11^{\text {th }}$ of April. This workshop consisted of a directed group discussion, reviewing and considering the evidence for and against the previously identified interdependencies, as well as any additional interdependencies that had come to light in the interim. This provided evidence justifying further consideration of additional interventions.

\section{Results of the Open Systems Framework Approach}

The application of the framework though these workshops resulted in the identification of 24 potential interdependencies between the HS2 Phase Two project and other infrastructure sectors which could enhance the core project proposal. Of these, five, were taken forward by the stakeholder group to identify further evidence for or against these interdependencies. Adopting an 'open systems' perspective allowed the stakeholders to view the HS2 Phase 2 project as more than a transport capacity solution, though there was perhaps a remaining focus on the route as a physical corridor. The 'open systems' approach facilitated the identification of inter-sector interdependencies, and arguably a conception of the project as a potential 'agent of change' within non-transport infrastructure sectors.

The five most significant interdependencies assessed can be summarised as:

- Using the High Speed 2 Phase Two corridor to provide additional electricity distribution capacity into Sheffield and Manchester: Combining HS2 Phase 2 with projects to enhance electricity distribution would consolidate and reduce visual blight and disruption during construction, though there would be issues over ownership, legislation and regulation. Economically, a single integrated project may be favourable as the total cost would be less than for two separate projects (e.g. for planning, consultation and tunnelling), and it would support and align increased economic activity in these regions. In social terms, city regions are expected to grow with the expectation that HS2 would also contribute to stimulation of population growth. This in turn means an increased electricity demand and a requirement for additional energy 
infrastructure. Technological impacts are expected to be minimal, though conductor technology may have advanced by the time of installation, increasing capacity as a matter of course. However, additional and diverse routing of the electricity network could improve overall resilience In terms of wider supporting evidence, a report by Frontier Economics [5] explicitly suggests considering the potential of other utilities (naming 'electricity transmission and distribution' providers) of using the rail corridor.

- Using the High Speed 2 Phase Two corridor to provide the capability for bulk water transfer between the north and the south: Politically this may be positively viewed in terms of its alignment with drought resilience policy. Economically this could be an expensive solution (around f2billion) with alternative schemes (e.g. from Severn Trent) providing cheaper options. However, implementing a bulk water transfer scheme is a significant project, added to which there is no immediate need: the water sector has established 25-year plans and water resources forecasts which indicate that a bulk water transfer scheme would be unlikely to be required in this timescale. Technologically the solution is known and robust, though could impact on the risk of a leak or burst pipe impacting on the track. It could improve resilience to drought, but the impact of climate change creates a great deal of uncertainty surrounding this option. It was reported in 2012 that United Utilities had considered the prospect of a $f 2.6$ billion North-South water pipe using the route of HS2[40], but also it was noted that Water UK is not currently in favour of bulk transfer schemes [41,42]. Overall, the workshop concluded that bulk transfer along the Phase 2 route would not provide sufficient benefit over a 25 -year time horizon to recommend it for further assessment.

- Using the High Speed 2 Phase Two corridor to provide the capability for inter-regional water transfer: From an economic perspective the pricing principles for trading across water regions is in place and such an approach could provide a cheaper alternative to other water resource development options such as long distance pipelines. For example, some water supply regions tend to be weakest at their extremities, so transporting water from neighbouring areas with an excess of water resources would be rational from a whole sector standpoint. It would also add to the resilience of the total UK water supply network and from an environmental perspective it could help regulators balance abstraction licensing against supply needs. The concept of water transfer between water companies and water supply zones has been explored by Water UK, and the United Utilities $55 \mathrm{~km}, f 120 \mathrm{~m}$ bi-directional pipeline between Manchester and Liverpool (West-East Link Main) is an example of the recent development of this type of infrastructure[43].

- Using the High Speed 2 Phase Two corridor (and associated construction) to provide the capability for additional flood protection: This Such an approach could be of significant socioeconomic value in terms of enhanced flood protection for householders and businesses in the affected flood plains, as being of interest to insurers and government agencies such the Environment Agency. Politically it would also be attractive if the HS2 Phase 2 project brought further benefits beyond the public transport sector. While the proposal is technologically achievable, it would come at additional costs, and furthermore the dynamic effects in flood plains are uncertain, and would combine with those uncertainties due to climate change and land use changes. Overall the workshop conclusion was that any scheme would be likely to create an overall positive benefit for the UK. It was noted that a report by Engineering the Future[44] supports the potential for the use of railway embankments as flood defences, whereas a joint report by DEFRA and the EA[45] indicates that existing rail embankment designs are not fit for flood defence purposes, although in some circumstances they may provide a partial barrier. 
- Using the High Speed 2 Phase Two corridor to provide additional capacity for the distribution of ICT infrastructure (e.g. fibre optic cables): The principal value would accrue by helping achieve UK national connectivity targets with less disruption than installing new separate ICT infrastructure. This option could offer diversity to the UK's ICT network, and may in the short term simply require a level of provisioning for future installation of ICT hardware. Wayleave agreements along the HS2 route would need to be established between interested parties, along with maintenance and access arrangements. Economically this opportunity could provide an efficient route, with low latency making the relocation of data centres outside London more attractive, and this in turn could create new job opportunities outside of the London area. It could also be used to boost rural economies along the HS2 route. A countervailing view was that the HS2 project may be too late to assist in achieving UK connectivity goals, and by the time the project is operational, the need for additional fibre cables (particularly for domestic use) may have been superseded by alternative wireless technologies such as $4 \mathrm{G}$. Further support in the literature for this interdependency includes the report by Frontier Economics [5] which explicitly suggests that other utilities such as 'super-fast broadband' should use rail corridors, and the OECD report [16] which proposes that transport networks include provision of a right of way for utilities to lay communication cables.

These interdependencies cross the traditional boundaries of infrastructure sectors. For them to be effectively considered in more detail would require HS2 Phase Two to be considered as more than a transport infrastructure project and more than the provision of additional rail capacity and reduced journey times.

The application of this framework has contribute to the High Speed 2 Phase Two Route Consultation, launched on the $17^{\text {th }}$ of July 2013 (and open until the $31^{\text {st }}$ January 2014). Paragraph 11.06 of the Phase Two Consultation document [46] states:

"We have been looking into whether provisions could be made along Phase Two of the HS2 network for other utilities such as water, electricity or integration with flood management schemes. This could further enhance the benefits brought to the country by HS2 while creating jobs and driving growth."

This concludes with consultation question (ix):

"Please let us know your comments on the introduction of other utilities along the proposed Phase Two line of route".

\section{Impact on the Framework}

In this application the framework provided a process for the facilitation of stakeholder discussions through an open system approach, as well as the systematic identification and holistic evaluation of cross-sector interdependencies. While the workshop provided a means to bring together a broad range of stakeholders, and the framework provided a structure to the process, the output was open to distortion from the beliefs of influential individuals. This led to the consideration of alternative complementary mechanisms through which to obtain stakeholder views. 


\subsection{Lower Thames Crossing}

\section{Background}

The existing Dartford to Thurrock Thames River crossing is an important part of the national, regional and local road networks. Studies have found that during peak times the existing crossing can act as a bottleneck in the network and traffic forecasts have indicated a need for increased future river crossing capacity in the region. As a result the National Infrastructure Plan 2012 [2] has identified the Lower Thames Crossing (LTC) as one of 40 projects of national significance.

There are many complex issues surrounding the capacity problem, the needs for a new crossing and the delivery of a solution. The literature concerning the LTC indicates that it is broadly conceived as a transport problem (albeit one that like all transport problems, can influence regional and national economies). This overriding transport perspective can influence the way in which a solution is developed and the way in which interdependencies with other infrastructure systems are identified and valued.

There are a large number of urban regeneration projects proposed for the area around the LTC. These can have an impact on the need for a new crossing and the demands that will be placed upon it. In turn, the existing and new crossing can impact on the delivery and success of these regeneration activities. Unlike the Northern Line Extension project (see following section), the LTC project is primarily motivated by a projected traffic capacity problem. It is clear from the existing documentation that the regeneration projects are planned to effectively proceed regardless of decisions surrounding the LTC project, and the LTC project will proceed largely independently of decisions involving the planned regeneration projects. Desirable and undesirable interdependencies may emerge between the LTC project and these regeneration projects either by design or by accident. The IP\&MF was applied here to better understand the potential interdependencies.

\section{Method}

The framework was initially invoked through a desk study of the relevant documents and available information concerning the Lower Thames Crossing and the regeneration projects in the region surrounding it. This was initially performed to explore the system boundary, understand the core needs and policies driving the project and to identify a broad set of stakeholders with interest in the potential interventions and there impacts. An open-system approach was taken in the study of the crossing and proximal regeneration activities which were assessed to identify auxiliary (to the Lower Thames crossing) socio-economic and environmental needs which could be met through interdependency. Tools associated with the application of the framework were applied to systematically identify cross-sector interdependencies highlights a number of necessary and potential interdependencies. These were then characterised and evaluated in terms of Political, Environmental, Social, Technological and Economic factors.

The output of this desk study was presented to a selection of the identified stakeholders who were given the opportunity to add interdependencies, re-characterise the identified interdependencies, reevaluate them, and provide additional evidence for this evaluation. Using the experience from the High Speed 2 Phase Two workshops a workbook was produced to gather feedback. Stakeholder engagement such as this provides the potential for a wider understanding of the architecture of the systems involved, the identification of conflicting or compatible needs and policies. In this particular case however, no further information was highlighted. 


\section{Results of the Open Systems Framework Approach}

Forty-eight high-level necessary and potential interdependencies were identified from the desk study. Some of these are only applicable if the crossing is placed in a particular location and takes a particular form (bridge/tunnel). Some are necessary for the crossing to function while others are potential interdependencies which may provide additional benefits to the LTC project, or may benefit external projects. Some may present risks to the LTC project or may enhance the efficiency of its delivery. The complete desk study and output can be found in the full LTC Case Study Report [11]. In line with current assessment criteria, the wider regional economic impacts of the crossing have been broadly considered, but there is little evidence that this has extended to a consideration of the project as a proactive 'agent of change'. Adopting an 'open systems' perspective allows for greater consideration of the ways in which interdependencies could be 'engineered' into the project to deliver regeneration in ways that extend beyond those classic associated with a transport solution. The additional, potentially valuable interdependency opportunities include:

- Using the Lower Thames Crossing structure to provide the capability for additional electricity generation: The specific nature of this would depend on the form of the crossing, but it is possible to use traffic vibrations, excess heat, photovoltaic cells or tidal mechanisms to generate electricity through the crossing structure. This could be done on a variety of scales, and could provide some of the electricity requirements for operating the crossing, its associated facilities and beyond. This would require placing energy sector infrastructure onto the transport infrastructure. The impacts of this interdependency would mostly be felt during the crossings operation. Like any inter-sector interdependency it would not be without organisational difficulties, but it would likely be seen as having a positive political, social and economic value. Its environmental value may depend on the exact form it takes. The notion of using the crossing to create a tidal lagoon, and for generating electricity was discussed by a 2009 Parsons Brinkerhoff [47] study into the LTC. This report noted that it was of interest although no specific need had been stated. Establishing this as a potential option would allow it to be considered further, and discussed with future crossing operators.

- Using the Lower Thames Crossing to provide the capability for cross-river distribution of electricity, telecommunications, water, and waste infrastructure elements: In some ways this is a relatively standard optional interdependency. If the crossing were a bridge, its structure could be used to distribute radio communication signals. Its role in terms of access and movement of waste (which could be by co-located pipework or vehicle based services using the crossing) have yet to be examined in detail, but could be of interest. While again, the integration of these infrastructure sectors would not be without their organisational complications, they could be of value from a political, environmental and social perspective. They could also add value to the project or allow for some construction costs to be shared.

- Using the Lower Thames Crossing structure to provide the capability for additional flood defences: This interdependency is also mentioned in the Parsons Brinkerhoff study, and relates to a proposal discussed as part of TE2100 [48] to construct a barrier/barrage across the Thames at Gravesham/Thurrock which would align with a potential crossing location. This may only be relevant in particular scenarios, but would be of benefit to local and regional stakeholders. The provision of such capability would require a significant departure from the conception of the LTC as a traffic solution and would require the boundary of the project to change. The value of such 
a scheme in its own right is complex and largely uncertain; its value as an interdependent provision with the crossing would require significant additional investigation.

- Using recycled materials in the construction of the Lower Thames Crossing: This would create a construction phase interdependency between the LTC and other local and regional projects. For example, other construction projects or the waste/recycling sector could provide materials for the road base or surface, and reciprocally the LTC could provide a means to 'dispose' of this excess material by putting it to use. This might be in the form of recycled aggregate, building materials or even car tyres (as implemented on the A90 between Perth and Dundee [49]). The large number of regeneration projects in the vicinity of the crossing, along with a number of industrial processing facilities, may make this possible. Further consideration of the value of this designed interdependency could leverage additional value for the crossings business case, both in terms of its own socio-economic and environmental value, and that of other external projects.

- Sharing resources between the construction of the Lower Thames Crossing and local regeneration projects: By fully considering regeneration projects underway in the region at the same time as the LTC's construction, it may be possible to create economic advantages both to the LTC project and the regeneration schemes. This may take the form of managed use of equipment and personnel or could involve aligned training schemes which could provide a legacy benefit for the region. There are also a number of large-scale national projects (such as High Speed 2) which may be under construction at the same time as the LTC which may provide efficiencies through aligned training and resource management, or may provide risks in terms of resource availability.

There is evidence from some of the recent studies into the LTC that interdependencies have been considered to a degree. For example the report by Parsons Brinkerhoff [47] mentioned above describes using the crossing to create flood protection, generating electricity and as an iconic structure, while a report by Aecom [50] mentions potential interdependency with congestion reduction at $\mathrm{J} 30$ of the M25, construction of a new Thames Barrier, the mooted Thames Estuary Airport, developments in Ebbsfleet Valley and the proposed Paramount Park on the Swanscombe Peninsula. However, the case study demonstrates that there are many more options which could be significant in affecting the impact of the crossing. Together with the Parsons Brinkerhoff and Aecom reports it would seem there is evidence for a more detailed study of some of these potential interdependencies. The evaluation of interdependencies, as implemented in this case study, could provide guidance for detailed future investigations.

\section{Impact on the Framework}

This case study allowed for additional development of the tools associated with the framework, as well as the testing of an offline stakeholder engagement mechanism. It supports the need and importance of adopting an open systems approach and exploring the system boundary. The LTC project is widely perceived as a transport project and the existing literature involves the study of the LTC's impact on transport and its interdependencies with other transport infrastructure. As with any transport project, the economic impacts (mainly in terms of agglomeration and increased labour catchments) are considered. Engaging with other infrastructure sectors, and other projects, may provide additional interdependency opportunities. When compared to the High Speed 2 case study and the following Northern Line Extension case study, this case begins to reveal the significance of the 
phase of the project during which the framework is applied and the perceived boundary of the project in relation to its socio-economic and environmental context.

\subsection{Northern Line Extension \\ Background}

The Northern Line Extension (NLE) is a local intraregional project to extend one of the 'deep' underground tube lines from its current southern terminus at Kennington to a new station at Battersea, via another new station at Nine Elms. The project is substantial in terms of the engineering involved and the costs. The project was one of those selected to receive a government guarantee as an attractor for the private sector to provide finance for the project. It is at present (July 2013) proceeding through statutory consultation as part of the necessary planning and legal regulations. Apart from being a major transport infrastructure project for London, a specific reason for considering the NLE was the mooted idea of the developers of the Battersea Power Station taking the waste heat generated by the operation of the tube train system and using it as useful heat or energy (via energy recovery technology). This offers the potential 'win-win' where a problem for TfL/LUL (paying for the extraction of the waste heat) becomes an opportunity for the developers of the major redevelopment they are planning. It is this type of positive interdependency that was hoped to be found if further links could be found.

The Northern Line Extension (NLE) project comprises the extension of the Charing Cross branch of the London Underground's Northern Line from Kennington to Battersea and the creation of two stations at Nine Elms and at Battersea. The latter will thus become the new southern terminus of the Charing Cross branch

This project is considered to be a key element in the package of measures supporting the planned regeneration of the Vauxhall-Nine Elms-Battersea (VNEB) area, namely one of the major Opportunity Areas (OAs) in Central London. The London Plan has identified the potential for a comprehensive renewal and intensification of the VNEB OA, in order to restore the degraded environment, promote the development of mixed use residential neighborhoods, and strengthen links with the rest of Central London.

On the basis of the above, it is evident that there is a strong interdependency between the NLE project (the line-haul plus its stations) and the proposed related development of the OA. On the one hand, a large-scale development of this kind may be achieved only with a concomitant intervention aiming to significantly enhance the currently poor level of public transport accessibility in the area. On the other hand, this massive transport project may be justified only on the basis of it spawning new related sustainable residential, commercial and leisure developments in compliance with prevailing plans and policies.

\section{Method}

For the purposes of this research project, the NLE case was conducted predominately via desktop study, although a small number of individuals involved in the project were contacted. Complementing the methods used in the previous case studies, the study of the NLE project has a strong focus on the wider policy context. The report also undertook a critical evaluation of the project against a set of criteria distilled from a selection of key findings and lessons learned from a five-year international study of decision-making in the planning, appraisal and delivery of mega transport projects involving 30 case studies in ten countries in the developed world undertaken by the OMEGA Centre [27]. A 
paper was also commissioned concerning Pension Fund Investment in Mega Infrastructure Projects and Related Developments [51] which, amongst other issues, explored the nature of NLE interdependencies from the viewpoint of the pension fund industry as potential investors in such infrastructure.

On the basis of the public domain documents reviewed by the OMEGA Centre and supplemented by the findings of the commission report, the report:

- provides a clear definition of the key characteristics of the NLE;

- analyzes the social and geographical context of the project, namely the VNEB OA;

- describes the regeneration projects proposed for the OA and the various infrastructures required to support this development;

- identifies and reviews the relevant national, regional and local planning and policy documents framing the NLE project and the planned regeneration of VNEB OA;

- defines the spatial boundaries of the NLE within which the analysis will be carried out;

- identifies the main NLE and VNEB OA stakeholders together with what is understood to be their agenda/objectives; and

- highlights possible strategic interdependencies between the NLE (as the line-haul plus its stations) and the other infrastructure projects included within the boundary of the megaproject (inclusive of the opportunity area).

\section{Results of the Open Systems Framework Approach}

Notwithstanding the numerous highly competent studies undertaken to date in association with the proposal to build the NLE project, an examination of the OMEGA findings [11] suggest that a number of noteworthy omissions exist in the NLE planning and appraisal processes if one is to consider it a megaproject that is critically dependent on (as it is) the success of related urban regeneration schemes and the effectiveness/efficiency of the independencies of other supporting infrastructure networks.

This more 'open-systems' perspective of project planning and appraisal implied by the OMEGA findings, and which looks well beyond the 'closed system' of the rail link and its stations and takes on board the 'agent of change' agenda it aspires to, warrants (it is contended) a Policy-Led Multi-Criteria Analysis (PLMCA) framework that facilitates the transparent prioritizing and contextualizing of tradeoffs amongst different key stakeholders regarding decisions about resourcing and costing the project, as well as determining where costs and benefits should/will ultimately fall over time, space and institutionally considering social and environmental criteria alongside economic and financial concerns.

A policy-framework of this kind clearly needs to be sensitive to what market forces deem viable. At the same time it needs to be cognizant of critical planning and regulatory measures. The OMEGA Study contends that the overarching UK government vision of sustainable development - expressed through international, national, regional and local policies, plans and legislation - should provide the leadership of such a PLMCA framework operationalized by policies and functional performance indicators $[4,27]$.

Whilst both the technical and the policy documents reviewed provide a clear indication of the aspired after 'agent of change' function envisaged by the construction of the NLE line haul and its stations namely to provide a step change improvement in transport connections in Battersea, Nine-Elms and 
South Lambeth in order to unlock the development potential of a number of urban regeneration opportunities within the VNEB OA - the appraisal process of the NLE project itself has been conducted on the basis of too narrow an economic analysis, even when considering the WEBs as identified by the Volterra Study [52]. Here the line haul study is essentially treated as a 'closed system' thereby preventing the use of more holistic integrated planning and appraisal frameworks that better identify the full extent of the broader costs, benefits, risks and opportunities - both of a monetizable and nonmonetizable nature - associated with the VNEB OA. This needs to be done by considering the technical, social, economic, environmental and institutional interdependencies between the line haul and the associated regeneration schemes and related infrastructure dependencies.

In particular

- The appraisal process of the NLE has been based exclusively on the line haul with the assessment of different route options being conducted without adequate consideration of the many other infrastructures required to support the development of the VNEB OA.

- The excessive dependence Cost Benefit Analysis (CBA) has the major proportion of social benefits identified for the scheme being made up of travel time savings, decongestion and crowding relief on the NL, whilst the economic costs are restricted to direct capital expenditure, renewal and operation expenses concerning the line haul and stations only. The wider costs and benefits associated with the regeneration of the VNEBOA including the required social infrastructure and the associated risks and opportunities, and identification of "winners" and "losers" (over time, space and institution) have not been adequately included in the appraisal or consultation exercises.

- Only the Battersea Power Station developers and possibly the American Embassy have been able to really influence this megaproject, while the remaining stakeholders have merely been asked to provide an opinion exclusively on the route options once that the extension had been already selected as the preferred transport solution. International evidence in Scandinavia suggests that early consultation with key project stakeholders can much reduce the opposition to projects further down the line and thereby avoid incurring additional costs that opposing appeals, for example, can generate.

The Report reiterates that a large-scale redevelopment/regeneration of the kind proposed for the Vauxhall Nine Elms and Battersea Opportunity Area (VNEBOA) may be achieved only with an associated improvement in public transport accessibility and capacity and on the basis of the findings from the Transport Study carried out by Sinclair Knight Merz, identifies the delivery of the NLE from Kennington to Battersea via Nine Elms as a key transport intervention for the development scheme. In this respect the NLE project and VNEB OA redevelopment are somewhat inherently interdependent, and seemingly more tightly coupled to one another than the LTC project and the regeneration projects in its region.

This coupling reveals both intra-system and inter-system interdependencies involved in the NLE \& VNEB OA. The nature of the intra-system interdependency is likely to be physical (interchange and integration), digital (signaling systems) and organizational (TfL, London Underground, Railways Companies, Buses Companies - Decisions relating to one part of the transport infrastructure system will have implications for other parts of the infrastructure system). Whilst many of these interdependencies are documented in feasibility studies and strategy document undertaken for the NLE \& VNEB, their full appreciation including consideration of attendant risks and opportunities is 
currently under-developed in the planning and appraisal frameworks adopted for the NLE \& VNEB OA. For example when specifying the provision of such supporting infrastructure, there is a tendency to use rule of thumb type calculations based on previous norms without a full appreciation of the risks and opportunities presented for intra-system infrastructure provisions by the unique context of the VNEBOA and the role of innovative solutions to infrastructure issues. Furthermore little consideration has been attached to impacts on particular infrastructure provision related to displacement both within out and outside the OA. The nature of the inter-system interdependency is likely to be physical (e.g. redevelopment projects around the stations), and organizational (e.g. concerning TfL and other major landowner and developers - with the decisions relating to one infrastructure system (transport) having important interdependencies with other sectors (i.e., real estate, social infrastructure systems etc.). In a similar way to the intra-system interdependencies, some of the inter-system interdependencies have been identified and documented by the various reports reviewed, such as the Section 106 payments due from the key developers of the site, but their full appreciation including consideration of attendant risks and opportunities is currently under-developed in the planning and appraisal frameworks adopted for the NLE \& VNEB OA. For example Lewin [51] provides a set of criteria for the identification of suitable infrastructure investments from the perspective of Pension Fund investors, and suggests a strategy by which inter- system interdependencies, such as the provision of long-term capital for infrastructure development by Pension Funds, may be encouraged. The incorporation of such strategies and criteria within the planning process, particularly via the IP\&MF framework early on in the development cycle, will help identify opportunities for strategic project interdependencies related to mechanisms for novel infrastructure financing.

The primary contributions of the NLE to the research are:

- That the potential for interdependencies span between all forms of infrastructure. In this case there is potential for interdependencies to arise between this underground metro project and:

- Other piped or cable utilities (electricity, gas, water, sewerage, ICT. These would be expected to be identified within normal consultation exercise

- Local buses, especially at points around station creation where traffic patterns will be expected to change. This interdependency would be expected to be identified within normal planning procedures

- Electrical power supply for the NLE will provided by $T f L$ and this may lead to further increase in generation capacity from national suppliers should TfL choose to source electricity from the market. This interdependency would be expected to be identified within normal planning procedures

- Remodelling of road layouts, including increased road user safety measures such as new or altered pedestrian light controlled crossings around new stations. This interdependency would be expected to be identified within normal planning procedures

- Impact on emergency services. The creation of new stations and other equipment needed for the NLE may cause issues for the London Ambulance Service, London Fire Brigade and Metropolitan police. Whilst concerns about the impact of the NLE would be expected to be identified through the normal planning application consideration, the opportunities for altering the scope of the project to seek improvements has not been identified as occurring in a 'round table' fashion. 
- Access to education and community health facilities. The provision of new stations will allow either the establishment of new social infrastructure facilities or their relocation. For example, colleges of further education may find themselves able to locate, relocate, or expand as a function of improved accessibility. There is no evidence of these potential opportunities being explored as part of the project shaping exercise.

The fact that the NLE was considered as an enabling project to 'unlock' the unrealised asset value of the redundant and degraded Battersea Power Station meant that for a long time this project was seen as a catalyst for the regeneration of the Battersea area in terms of attracting inward investment primarily from private developers. This emphasis has been increased given the decision to install an interstitial station as Nine Elms and in so doing has confirmed the attraction of a number of interested parties keen on exploiting the area's latent appeal. This interest is notable for including foreign government embassies led by the USA. Such an 'attractor' as the US Embassy would itself lead to further interest from other developers as this area moves from hinterland status to a busy (and well connected) area. Whilst this is all extremely positive, it raises issues about what these new areas will need to fully support the residents and other occupiers moving to the area. Whilst the hard economic infrastructure will be considered (demand calculations for electricity, gas, potable water, sewerage will all be expected to be captured as part of the consultation exercise), there may well be opportunities to look at wider interdependencies arising from the NLE, especially as tube stations in particular generate opportunities for many services: from health and education, through to retail and leisure.

This suggests ceterus paribus that the NLE is a positive infrastructure project, but the question remains - could it be even better? In considering this, lessons were learned from the current upgrade works taking place across other parts of the LUL underground station network. In particular the experience of the work being done at Tottenham Court Road station is considered valuable. The station is being radically upgraded to allow it to cope with expected increases in customer numbers driven by both standard patterns of use (historically rising with no sign of abating) and the extra passengers using the Crossrail service). However, the major intervention needed to carry out this work has led to the opportunity to look at the road layout at a major traffic interchange where there large traffic road volumes meet large numbers of pedestrians. Through widening the scope of the station upgrade to include new layouts to roads and pavements, it is planned that more pedestrian traffic can flow between this area and Covent Garden - some hundreds of metres away. At present the layout is poor and pedestrians find it unattractive to move from to Covent Garden from Tottenham Court Road and vice versa. If the layout is changed (triggered by the underground station upgrade) then not only would this make a more pleasant area (the value of which is not easily monetised), but it would directly affect footfall and expected retail spend, which would have positive impacts on job creation and business rate tax collection.

In comparison, the NLE case has not looked at this more micro-level opportunity centred on the stations. The overall objective is clear and is highly likely to succeed as the evidence from the Canary Wharf area and the Jubilee Line Extension has demonstrated, but it remains unclear as to what more could have been achieved if from the outset the ambitions were set as being regeneration via both private sector and public sector investment and interaction? 


\section{Impact on the Framework}

This case study allowed for additional development of the tools associated with the IP\&MF, particularly those related to the application of a normative framework for megaproject appraisal derived from the OMEGA Centre findings [4 and 27] and the potential role of PLMCA to help identify broader interdependencies within the realm of strategic project decision making.

A further direct finding of this case is the appreciation of the need for the consideration of interdependencies to occur at the correct time in the project lifecycle. In the case of the NLE the project was too well formed and 'locked in' and so consideration by those driving the project of fundamental interdependencies along the lines described in the final paragraphs of the previous section would have considered as moving the project backwards - something all project managers are trained to resist. The NLE project is to a certain extent in purdah as the project is entering the period of statutory consultation. During this phase it is likely that negative interdependencies will be identified as those either affected by or needing to feed into the NLE will identify their issues. Thus there will be stage preceding this (outlined above) where the scope and strategic objectives can be considered (this stage more suited to the policy-led/informed Multi Criteria Analysis and Stakeholder Engagement approach) and then after statutory consultation has taken place (providing significant clarity on the project at a more granular level) there will be a chance to consider the 'second-stage' interdependencies (positive) that may arise from combining certain aspects of the NLE works with others - so for example advantage can be taken by other piped/cabled utilities of the new tunnels being created.

\subsection{Engineering the Future Infrastructure Timelines \\ Background}

Though not part of the initial Case Study infrastructure projects identified by Infrastructure UK, elements of the IP\&MF were applied to the policies and projects documented in Engineering the Future's original Infrastructure Timelines [53]. These timelines capture the next 40 years of UK infrastructure planning across five infrastructure sectors (Energy, ICT, Transportation, Waste, Water). The useful visualisation documents the known policies and plans in these sectors, together with expert opinion of future policies and projects from the engineering community. The framework was applied with the aim of assisting Engineering the Future in the delivery of the second phase of the timelines project, by helping to identify areas where a lack of planning and appreciation for interdependency could lead to failures across interdependent sectors, and where it could result in beneficial interdependency opportunities being missed.

The cross-sector nature of the Infrastructure Timelines arguably lend themselves to an open-systems view of interdependency. The boundary of these projects collectively is drawn broadly, encompassing the five infrastructure sectors, as opposed to a single sector or project as is perhaps more common. The workshop was held on the $4^{\text {th }}$ of February 2013 at The Royal Academy of Engineering and brought together a diverse set of 25 infrastructure stakeholders from across the five timeline sectors $[13,14]$. This included representation from industry and academia, as well as those involved with infrastructure governance, each having an interest in the policies, projects, interventions, and their impacts. The inclusions of policies across the five sectors of the timelines went someway to identifying the wider policy context including socio-economic and environmental needs which were not necessarily directly related to the projects under investigation. 


\section{Method}

The workshop consisted of three sessions. The first session, of approximately 45 minutes, took the form of a brief tutorial. This set out the background to both the Engineering the Future timelines project and the IP\&MF project. The theoretical underpinnings of the IP\&MF were also discussed along with the basis of the matrix-based tool which was to be used during the two following break-out sessions.

During the first session the attendees were split into four groups such that each group was comprised of experts primarily based within one of the five timeline sectors. Due to the distribution of expertise, the ICT and Waste sectors were grouped together such that one group represented both of these sectors. This first phase allowed for a detailed investigation of the policies, needs and projects within that sector.

The participants selected five projects or policies relevant to the sector they were representing. A free choice was provided so that they could pick a selection about which they had the most knowledge. This means that the selections do not necessarily represent the most critical projects and policies. While there are clearly advantages to specifically identifying and analysing the most critical policies and projects, the free choice ensured a good collective knowledge, and therefore a higher likelihood of identifying the interdependencies. This does not remove the possibility that some policies and projects may have been chosen on the basis of importance. A systematic process was invoked to identify and characterise the necessary and potential interdependencies between the sector-specific projects, thus identifying intra-system interdependencies. These interdependencies were assessed by the stakeholders in terms of whether they presented interventions which were largely beneficial or interdependencies which added to the projects' risk profiles.

For the second workshop session the participants were re-grouped such that each group was comprised of representatives from multiple sectors. During this session they were asked to consider the projects and policies from the first session, along with any others they were familiar with, at the aggregate level of the entire sector. From this position they discussed and recorded the interactions between the five timelines sectors using the same systematic process as the first session. Through this activity they identified the inter-sector interdependencies.

\section{Results of the Open Systems Framework Approach}

Collectively, ninety-two interdependencies were identified by the four sector specific groups. The group look at interdependencies within the energy system (energy intra-system interdependencies) identified 27 relationships between five projects/policies identified in the timelines (Smart Grids, Exiting Building Use, Nuclear, Heating and Community Energy and Gas). The Smart Grid project (and associated policies) was identified as being a significant potential opportunity when integrated with the other elements, providing the means to optimise their performance. It was also noted that achieving the potential benefits of Smart Grids was dependent on projects within the ICT sector.

The transport sector group identified 15 interdependencies between the five sector projects/policies. Collaboration accounted for five of the identified relationships, four of which involved the ownership and funding of the highways network. For example it was felt that collaboration on Business Cases would be advantageous between the stakeholders involved in highways funding and those involved with managing airport capacity in the South East, HS2 stakeholders and London Gateway stakeholders. The groups' discussions focused on the interaction between national and local road usage. Night time 
use of the motorways presents an underutilised asset, however local policies restrict the nocturnal movement of freight. This is the sort of issues which could arise from the integrated approach to Business Cases, especially concerning highways ownership, airport capacity and London Gateway. Collaboration over issues such as this could help leverage underutilised opportunities from such interdependencies, which may ultimately be beneficial to a project's Business Case. During the discussions within this group, it was noted that HS2's benefits are not limited to the boundary of a rail project. One of the wider benefits comes in the form of potentially removing traffic from the highways and therefore contributing to the emissions reduction strategy. Reciprocally, the restrictions placed on HS2 by emissions reduction policies were discussed

The group looking at both the ICT and waste systems focused on three projects/policies from the waste sector and three from the ICT sector. The group also looked at 'Space Assets' in terms of both ICT and waste. Despite not featuring in the original timelines, the expansion of 'Internet of Things tagging' (through RFID tags or QR codes) was revealed to be a particularly interdependent project with widespread potential benefits. It was an element in 9 of the 25 relationships. Like Smart Grids this is an example of an emerging technology which could provide additional benefits, especially in terms of data, if integrated with other projects. It was thought that Internet of Things tagging could provide benefits to the recycling of rare materials, the identification and tracking of suitable feedstock from waste for anaerobic digestion, and the location and classification of space assets. The effectiveness of this is itself dependent on a resilient and capable convergent broadband system with suitable national and local coverage. This in turn could be delivered by suitable underused interdependencies with existing and future Space Assets (i.e. satellites).

The final group identified 24 relationships between the five planned projects/policies they investigated as part of the water infrastructure system. Many of these involve necessary physical relationships involved in the transfer of water. This includes how flood waters can become part of the bulk supply, can recharge aquifers and therefore impact on abstraction, as well as creating pollution by increasing run off, damaging industrial facilities and affecting water treatment plants. Some of the most interesting situations arise from 'second-order interdependencies' - where the effect of one element is felt on another via their mutual relationship with a third - or even higher order interdependencies. These can be more subtle and difficult to identify, but several were made apparent from the application of elements of the framework.

The output from the second phase identified 84 inter-sector (or inter-system) interdependencies. As with the intra-sector analysis, it is possible to identify second-order or higher chains of interdependency relationships. These can form feedback loops. For example, the energy sector provides electricity to power pumping and treatment systems within the water sector. Water treatment can result in the production of 'bio-sludge' as a waste product. The waste management infrastructure sector can provide this 'bio-sludge' to the energy sector for use as a feedstock for anaerobic digestion which can be used to produce biogas for electricity generation.

There is a strong relationship between ICT and Transport. Some of these are in the form of unutilised opportunities such as ICT providing the capability to reduce the need for physical travel (e.g. the ability to videoconference), while others relate to co-location of assets, the provision of services (such as route planning) and systems (such as congestion charging infrastructure). While the Transport sector relies quite heavily on the ICT sector for some services, very little was identified in the other direction. 
The Energy sector is strongly linked to each of the other four sectors. It provides necessary power to aspects of the ICT sector and relies on it for control systems. The utilisation of Smart Metering can affect energy usage and demand management. Energy distribution and Transport assets can share the same physical space and the Energy sector provides the Transport sector with fuel (petrol and electricity for EVs) and lubricants. The Transport sector in turn provides the capability to move Shale Gas and other fuels.

There is an identified need to align Transport sector and Energy sector policies in order to avoid a potential failure from a lack of interdependency planning. From the discussions held, this seemingly refers to the need for collaboration between sectors to plan for the possible increase in electricity demand, should there be a significant switch to electrical vehicles. While there is some suggestion that domestic EV charging may take place in off-peak periods, there is still a need for interdependency planning in this area. There is a need to ensure policy concerning the uptake of EVs and the development of the supporting infrastructure supports policy concerning energy use and vice-versa. Harnessing excess vehicle heat from tunnels as a source of energy is also identified as a potential underutilised interdependency between these sectors.

\section{Impact on the Framework}

Once again this application allowed for the development of the approach and tools associated with the framework and provided an insight into stakeholder engagement and interaction with the framework. The cross disciplinary nature of Engineering the Future (the leadership is provided by the Engineering Council, Engineering UK, the Institution of Chemical Engineers, the Institution of Civil Engineers, the Institution $f$ Engineering and Technology, the Institution of Mechanical Engineers, the Institution of Physics and the Royal Academy of Engineering) and their Infrastructure Timelines provided a strong starting point and impetus for stakeholder engagement with the framework. The set of projects and policies had already been established and the participants were informed about the growing interest in identifying interdependencies. Although the participants engaged in the process and provided useful insights, it was evident from that there is a need for a clear, mutually agreed definition of interdependency, the different forms it can take and how better knowledge of interdependencies can be used.

\subsection{Case Study Conclusions}

The main Case Studies investigated three significant UK infrastructure projects, applying elements of the IP\&MF in each case. The application of the framework revealed several infrastructure interdependencies which have the potential to deliver benefits to the infrastructure projects in question, as well as wider benefits to other infrastructure projects, society and the economy.

The Case Studies demonstrated that the framework provided a means to identify, characterise and evaluate these interdependencies, which can then be subjected to additional detailed study based on their valuation. They show, be revealing multiple interdependencies, that there is potential for the identification and management of interdependency within and between infrastructure projects which goes beyond the status quo.

In general, the Case Study applications have focused on revealing interdependencies between a specific infrastructure project and other external existing and planned infrastructure elements. These can arise from the co-location of physical assets, exploiting an unharnessed or underused capability of an asset or service, sharing resources or utilising waste outputs. 
Interdependencies can be hidden if the boundary of the project is drawn tightly around a particular challenge or need faced by a specific sector. The purpose of a project may change through a better understanding of the whole environment of stakeholder infrastructure needs. The framework facilitates the means by which to explore needs and challenges external to the core project in a meaningful search for interdependencies which may positively benefit one or more of the projects. However, despite this general focus of the Case Studies, the negative impacts of known and unknown interdependencies are also very important.

The framework's application in these Case Studies helps to make explicit the interdependencies which are necessary for the Case Study projects to function efficiently. These can then be better managed to reduce the risks associated with common cause, cascade and escalating failures.

Developing and managing these interdependencies may help improve the efficiency, reliability and resilience of the whole infrastructure system of networks, as well as the business case for specific projects though better stakeholder understanding.

The facilitated interaction of a wide range of infrastructure stakeholders revealed that the High Speed 2 Phase 2 corridor could be used to provide or assist in delivering other potentially valuable infrastructure projects. Thus this core project could adopt the role as an 'agent of change' in part facilitating other infrastructure policies and projects. This includes providing: additional electricity distribution capacity into Sheffield and Manchester; the capability for inter-regional water transfer at key locations; the capability for additional flood protection; and, the capability for distributing additional ICT infrastructure.

A desk study of the Lower Thames Crossing project identified and assessed a number of opportunities arising from exploiting additional interdependencies or engineering new interdependencies. The positive impact of the interdependencies may be mainly experienced external to the Lower Thames Crossing Project or may be beyond the existing conceived boundary and purpose of the project as a solution to a transport challenge. For example the crossing could provide the capability for additional electricity generation and utility distribution. It could help facilitate the construction of additional flood defences and, as part of its construction, provide a use for waste products such as tyres. The region around the proposed Lower Thames Crossing is the focus for several social and economic regeneration schemes. There are opportunities for positive and negative interdependencies to arise between the crossing and several regeneration projects, but they are ultimately loosely coupled from one another.

An in depth study of the Northern Line Extension project provided additional insight into the reasons why such interdependencies are not widely considered. In this case it was observed that the appraisal process for the project was based exclusively on the line haul without adequate consideration of the potential interactions with the other infrastructure elements required to achieve the wider, but closely associated, urban regeneration policy goals. The fact that the Northern Line Extension project is relatively tightly coupled with the regeneration schemes, yet these interdependencies were still not appropriately considered, is perhaps evidence that the current approach is not adequate and encourages a closed-system view. The study of the Northern Line Extension project also revealed a dependence on Cost Benefit Analysis and a narrow appreciation of the wider stakeholder needs. These can unduly constrain a project, discouraging an appreciation for the wider costs, benefits and requirements, and hindering the consideration of interdependencies. 
As well as providing additional insights and understanding to the Case Study projects, these applications also allowed for the framework to be developed and refined. They highlighted:

- A need for broad stakeholder engagement and a need to overcome the cultural and organisational barriers which may hinder this. There was indication of a tendency to draw a closed boundary around a project, restricting it to a particular infrastructure sector, and discouraging the consideration of interactions across the boundary. This can restrict stakeholder involvement. There is a need for further study into the nature of these barriers and how the framework can assist in overcoming them;

- A need for a clear definition of interdependency in relation to infrastructure projects and policies. This could involve examples of interdependencies having positive and negative effects as well as cases where interdependencies have been identified and managed successfully and where they have not. The cases discussed in this section and elsewhere in the report may assist with this;

- As discussed in Section 4, the phase of the project lifecycle in which the framework is applied is relevant to the success and scale of the potential innovation. If the 'solution' and its purpose are already firmly resolved (e.g. Northern Line Extension), if the boundary of the problem and its solution are well established (e.g. Lower Thames Crossing), then it can be difficult to consider and value significant, innovative interdependency opportunities. A high level appreciation of potential interdependencies early in a projects planning may be beneficial, coupled with more detailed assessments at later stages in the design process. 


\section{Conclusions}

The leading conclusion is that it is proved possible, but not easy, to explore the potential positive interdependencies that are anticipated as existing on infrastructure projects. Whilst the research team at University of Bristol and UCL believe they have addressed the principles of the brief, the project has not produced a simple mechanism that can be inserted into the existing project appraisal process. To attempt to do so would trivialise the potential for benefits to emerge from the consideration of such interdependencies and would run the danger of being seen as a necessary chore triggering a 'tick-box' mentality. For the richest vein of interdependencies to emerge the project sponsors or owners need, from the earliest outset of the idea for the project, to be considering where such interdependencies may occur and which parties to engage with. This can be summarised as a move towards the principles of 'stewardship'. This should be considered as both a conclusion and implicit recommendation.

In terms of more direct conclusions, the following points are made:

1. An IP\&MF has been developed and implemented comprising principles, practice and organisational maturity, and example methods and tools, and it responds to the work programme set out in the proposal.

2. A description of an IP\&MF process has been presented, together with an implementation of this based around PESTLE, matrix mapping and MCA, but noting that other tools could be used to implement the framework.

3. Elements of the framework have been tested in the three final case studies. The degree of testing has not been as extensive as we would have liked, and not all elements of the framework have been tested in all case studies. However, the implementation applied to the case studies was accepted by the participating stakeholders, and the test results bear this out.

4. The failure to conduct full testing on all three cases reveals the essential and implicit need for the leading project players to understand and appreciate the potential value of conducting such an interdependence search exercise. Where this is not recognised it will probably have been considered as an unwelcome distraction.

5. The evidence from the OMEGA centre research clearly indicates the need for engagement and involvement with a wide range of stakeholders early on in the project lifecycle, before the project is committed in terms of definition and scope.

6. The OMEGA centre's previously completed research led to their proposal of a policy-led MCA approach to projects that are similar to the mega transport projects that it studied. This is strongly supportive of open systems approach, with central focus on the importance of understanding the various contexts in which the proposed project is set.

7. The importance of interdependency management is now beginning to be widely recognised including by Government. This is evidenced in recent reports from both credible authors - Frontier Economics and on nationally significant projects such as the recent HS2 Phase 2 consultation.

8. In conducting this research the research team can find no evidence of any other country that would be comparable to the UK where the thinking and actions related to interdependency is as advanced. Countries like Singapore and territories like Hong Kong have considered such 
interdependencies, but they have significantly different histories and national profiles to the UK. We believe that this work puts the UK in the vanguard.

9. Recommendations have been made for implementation of an Annex to the Green Book. 


\section{Recommendations}

In addition to the conclusions in the previous section, the development and application of an Interdependency Planning and Management Framework has led to the following recommendations:

Recommendation 1: That a stewardship function is established by Government with the purpose of overseeing the integration of infrastructure planning, delivery and operation.

A key principle of the interdependency planning approach set out in his report is that effective and efficient strategic governance or 'stewardship' of infrastructure requires a shift away from an individual and myopic asset management perspective. This move to a principle of stewardship requires a wide range of institutions and enterprises to collaborate in developing a coherent framework of policies, plans, processes and institutions to guide infrastructure investment and planning against some long-term vision. The stewardship role set out in the IP\&MF will have a critical impact in determining how infrastructure interdependencies will be framed and assessed during the project appraisal process, and in promoting the collaborative approach needed to identify beneficial interdependencies across Government, regulators and industrial sectors. The proposed IP\&MF would require Government to:

1. Oversee the integration of infrastructure development over the long term, within a framework that balances current socio-economic and fiscal needs with longer term ecological sustainability and asset value;

2. Define planning policies and investment priorities which are sufficiently flexible and responsive to changes in technologies, socio-economic policy and the natural environments;

3. Support local and national government departments, regulators and commercial enterprises in developing their capacity to create and manage interdependencies successfully.

Recommendation 2: That an Open Systems approach be used to underpin the Green Book Interdependency Planning and Management Process.

The National Infrastructure Plan 2011 [2] notes that for the UK "opportunities to maximise infrastructure's potential as a system of networks have not been exploited". An 'open systems' approach to interdependency management should be adopted by Government since this would provide policy makers, economists, planners and engineers with three important principles from which to plan and manage infrastructure interdependencies. These are:

1. That infrastructure development requires a holistic view of infrastructure as a network of interconnected and evolving systems which is consistent with a 'system of systems' perspective of infrastructure.

2. That all 'hard' infrastructure systems are developed within a framework of 'soft' systems comprising policies, processes and practices, coupled with the institutions, organisations and people that define and implement them.

3. To question and explore the accepted and/or perceived system boundary for an infrastructure development in order to engage with a wider range of stakeholders and create the potential for innovative project scoping and design options.

Recommendation 3: That there is a need to embed learning and maturity modelling in order to inform the development of policy and practice in planning and managing infrastructure interdependency. 
The success of initiatives to implement and develop interdependency planning and management practices will depend on the behaviours and knowledge built up in the infrastructure policy, planning, engineering and management communities. The application of knowledge also has to go beyond understanding what has been done here in the past, and must also meet the challenge of what can we achieve dependably in the future. Set against this interdependency planning and management represents a relatively new and challenging set of policies and practices. There is therefore a clear benefit to be gained from embedding learning and organisational maturity modelling processes in any initial IP\&MF and in sharing best practice if costly mistakes are to be avoided in the meantime. It is therefore recommended that generic learning is abstracted during the post-project evaluation stages of infrastructure development, and made available to support other infrastructure development projects.

However, OMEGA centre research indicates that lesson-learning and sharing is not currently a significant feature of infrastructure specification, planning, appraisal and delivery, and that frequently knowledge acquired by the private sector is guarded for commercially competitive gain. It is therefore recommended that Government considers a suitable mechanism for abstracting, generalising and sharing of 'good practice' and key lessons learned through 'knowledge sharing platforms. The aim of his should be to ensure public investment in infrastructure is as efficient as is practicable.

Once understanding, familiarity and confidence with the initial implementation has been achieved, so it will be both possible and desirable to move to improved and advanced levels of IP\&MF.

\section{Recommendation 4: That business models and practices are needed which seek to promote openness and collaboration in the creation and operation of infrastructure.}

The greatest benefits for interdependency planning will accrue when there is early participation from across different sectors in this process, including the input of cross-disciplinary knowledge. Business models and practices should be promoted where these are likely to encourage a broad-based engagement with a plurality of stakeholders, and the 'opening up' of the infrastructure planning and design process to innovative and collaborative proposals. In normal circumstances, traditional project management vies and commercial interests may stand as a barrier to full openness and collaboration, and there is therefore a role for Government actively to promote collaborative approaches to infrastructure planning and management, in particular when this involves public investment. 


\section{References}

1. McKinsey Global Institute. Infrastructure productivity: How to save \$1 trillion a year. 2013.

2. HM Treasury, Infrastructure UK. National Infrastructure Plan 2011. 2011.

3. Omega Centre UCL, Dimitriou HT, Harman R, Ward EJ. Incorporating Principles of Sustainable Development within the Design and Delivery of Major Projects: An international study with particular reference to mega urban transport projects, Final Report. London: OMEGA Centre, University College London ; 2010.

4. Omega Centre, University College London. Investigation into the Development of a Framework for the Identification and Appraisal of Infrastructure Interdependencies with Application to Critical UK Infrastructure. London; 2012.

5. Frontier Economics. Systemic Risks and Opportunities in UK Infrastructure - A Report Prepared for HM Treasury \& Infrastructure UK. 2012.

6. Australian Government - Australian Public Service Commission. Tackling Wicked Problems A Public Policy Perspectve. 2007.

7. Rittel HWJ, Webber MM. Dilemmas in a general theory of planning. Policy Sciences. 1973;4(2):155-69.

8. Council for Science and Technology. A National Infrastructure for the 21st Century. 2009.

9. HM Treasury. The Green Book - Appraisal and Evaluation in Central Government. 2003.

10. Rosenberg, G. and Carhart, N. Review of Potential Infrastructure Interdependencies in Support of Proposed Route HS2 Phase 2 Consultation. Case Study Report for Infrastructure UK and the Department for Transport. Final Report Published 30th October 2014. http://dx.doi.org/10.14324/20141455383.

11. Carhart, N. Identification of High-level Infrastructure Interdependencies for the Lower Thames Crossing. Case Study Report for Infrastructure UK. Final Report Published 30th October 2014. http://dx.doi.org/10.14324/20141455371.

12. Ward, J. Phase 2 Desk Study Report of Northern Line Extension. Case Study Report for Infrastructure UK. Final Report Published 30th October 2014. http://dx.doi.org/10.14324/20141455361.

13. The Systems Centre, University of Bristol. Workshop Application of a Matrix Based Approach to the Identification of Infrastructure Interdependencies - Workshop Report for Engineering the Future. 2013.

14. Engineering the Future. UK Infrastructure Timelines. 2011.

15. Rosenberg, G. \& Carhart, N. (2014). A Systems-based Approach to Creating Value from Infrastructure Interdependencies. In: Campbell P. and Perez P. (Eds), Proceedings of the International Symposium of Next Generation Infrastructure, 1-4 October 2013, SMART Infrastructure Facility, University of Wollongong, Australia. http://dx.doi.org/10.14453/isngi2013.proc.39

16. OECD. Infrastructure to 2030: Telecom, Land Transport, Water and Electricity. 2006.

17. HM Treasury. Valuing Infrastructure Spend: Supplementary Guidance to the Green Book. 2011. 
18. Carhart, N. and Rosenberg, G. Towards a Common Language of Infrastructure Interdependency. Presented at the International Symposium for Next Generation Infrastructure, IIASA Vienna, October 2014.

19. Zachman JA. A framework for information systems architecture. IBM Systems Journal. IBM; 1987;26(3):276-92.

20. Lano RJ. A technique for software and systems design. Elsevier North-Holland Pub. Co.; 1979. page 119.

21. Morris PWG. Reconstructing Project Management. Wiley-Blackwell; 2013. page 342.

22. HM Government Cabinet Office. Strategic Framework and Policy Statement on Improving the Resilience of Critical Infrastructure to Disruption from Natural Hazards. 2010.

23. Lin JY. New Structural Economics: A Framework for Rethinking Development. World Bank Publications; 2012.

24. Centre for the Protection of National. The national infrastructure [Internet]. Centre for the Protection of National Infrastructure; [cited 2012 Oct 17]. Available from: http://www.cpni.gov.uk/about/cni/

25. Von Bertalanffy L. General System Theory: Foundations, Development, Applications. George Braziller; 1968.

26. Beckford J. Systems Engineering: Necessary but not Sufficient for 21st Century Infrastructure. 2013.

27. Omega Centre, University College London. Mega Projects and Mega Risks: Lessons for Decision-makers through a Comparative Analysis of Selected Large-scale Transport Infrastructure Projects in Europe, USA and Asia Pacific, Final report of a five year international research programme. London; 2011.

28. Morris P. Initiation strategies for managing major projects. In: Dinsmore A, Cabanis-Brewin J, editors. The AMA handbook of project management. 2nd ed. 2006. page 31-43.

29. Edkins A, Geraldi J, Morris P, Smith A. Exploring the front end of project management. Engineering Project Organization Journal. 2013;3(2):71-85.

30. Morris PWG, Hough GH. The anatomy of major projects: a study of the reality of project management. Chichester: Wiley; 1987.

31. Miller R, Lessard DR. The strategic management of large engineering projects shaping institutions, risks and governance. Cambridge, Mass.: MIT Press; 2001.

32. National Audit Office. Department of Health: the National Programme for IT in the NHS: an update on the delivery of detailed care records systems: report, HC Session 2010-2012. London; 2011.

33. The Environment Agency. River Restoration: A stepping stone to Urban Regeneration Highlighting the Opportunities in South London. 2001.

34. Senge PM. The Fifth Discipline: The Art and Practice of the Learning Organisation. London: Century Business; 1990.

35. The Systems Centre U of B, The Bartlett faculty of the built environment $U$. Exploring the potential for installing dark fibre on the HS2 pathway. 2012.

36. Rinaldi SM, Peerenboom JP, Kelly TK. Identifying, understanding, and analyzing critical infrastructure interdependencies. IEEE Control Systems Magazine. 2001;21(6):11-25. 
37. Ventura CE, Juarez Garcia H, Marti JM. Understanding Interdependencies Among Critical Infrastructures. Proceedings of the 9th U.S. National and 10th Canadian Conference on Earthquake Engineering. Toronto; 2010.

38. Department for Communities and Local Government. Multi-criteria analysis: a manual for good practice. 2009.

39. Government Office for Science. Blackett Review of High Impact Low Probability Risks. 2011.

40. Drought pipeline proposal for HS2 route | Magazine News | New Civil Engineer [Internet]. Available from: http://www.nce.co.uk/news/water/drought-pipeline-proposal-for-hs2route/8627114.article

41. Water UK says High Speed 2 water pipeline could be "insurance policy" [Internet]. [cited 2013 Aug 1]. Available from: http://www.waterbriefing.org/index.php/home/waterissues/item/5418-water-uk-says-high-speed-2-water-pipeline-could-be\%E2\%80\%9Cinsurance-policy\%E2\%80\%9D].

42. House of Commons - Uncorrected Transcript of Oral Evidence - HC 1852-iii: Oral Evidence taken before the Environent, Food and Rural Affairs Committee "The Water White Paper" [Internet]. 2012 [cited 2013 Aug 1]. Available from: http://www.publications.parliament.uk/pa/cm201012/cmselect/cmenvfru/uc1852iii/uc185201.htm

43. Case Study: West East Link pipeline [Internet]. [cited 2013 Aug 1]. Available from: http://annualreport2011.unitedutilities.com/WelmCS.aspx

44. Engineering the Future. Infrastructure, Engineering and Climate Change Adaptation ensuring services in an uncertain future. 2011.

45. Morri M, Dyer M, Smith P. Management of flood embankments: A good practice review. 2007.

46. HS2 Ltd. High Speed Rail: Investing in Britain's Future - Consultation on the route from the West Midlands to Manchester, Leeds and Beyond. 2013.

47. Parsons Brinkerhoff. Dartford River Crossing Study. 2009.

48. Environment Agency. Thames 2100 Plan: Managing flood risk through London and the Thames estuary. 2012.

49. Innovative approach to resurfacing road - South Lanarkshire Council [Internet]. 2013 [cited 2013 Aug 1]. Available at: http://www.southlanarkshire.gov.uk/press/article/686/ innovative_approach_to_resurfacing_road

50. Aecom. Review of Lower Thames Crossing Options: Final Review Report. 2013.

51. Lewin, C. Pension Fund Investment in Mega Infrastructure Projects and Related Developments. Commissioned paper prepared by Chris Lewin, FIA, FSS, FPMI (actuarial and pensions specialist) with support provided by Dr. E. John Ward and Prof. Harry T. Dimitriou of OMEGA Centre, UCL. 14 July 2013

52. Volterra Partners. The Wider Economic Benefits of the Northern Line Extension in the Vauxhall, Nine Elms, Battersea Opportunity Area. 2012.

53. Engineering the Future. Infrastructure Interdependencies Timelines. 2013.

54. DTLR (2001). Multi-criteria analysis: a manual. Department for transport, local government and the regions. Updated 2009. Accessed October 2014: https://www.gov.uk/ government/uploads/system/uploads/attachment data/file/7612/1132618.pdf. 


\section{Appendix A Interdependency Planning and Management Framework Specification}

The table of requirements defined in this Appendix compiles the high-level functional specification for the development of the IP\&MF, addressing organisational, programme and project aspects, against which the completeness of the preliminary framework was assessed. It also provided the basis for planning test case applications, and a means of assessing the degree of success from the resultant test case outcomes.

\section{Requirement Area}

1. The Framework Shall Provide a Systematic Process for Identifying and Handling

Infrastructure Interdependency

\section{Detailed Requirements Specification}

a) Infrastructure interdependencies can be complex, multi-dimensional and dynamic in nature, and are not immediately apparent from an analysis of direct linkages between hard infrastructures. Tools shall facilitate exploration and identification of complex links between soft and hard infrastructure systems.

b) The framework shall be capable of facilitating the integration of infrastructure through planning and engineering processes. It shall provide for the identification of both potential beneficial interactions (opportunities) and possible adverse interactions (risks) and thereby facilitate designs for enhanced value-for-money and increased resilience respectively.

c) The approach shall be systematic and logical, and ensure a wider conception of interactions is captured managed than is achieved with existing approaches. This shall facilitate a wide search across sectors, knowledge domains, stakeholders, policy owners, and include the soft aspects of social-economic and legislative systems. This will need to go beyond the physical asset level to look at the potential policy, sector, stakeholder need and capability interdependencies.
2. The Framework Shall Support a Process of Continual Improvement in the Handling of Infrastructure Dependencies a) The planning, appraisal, design and operation of national infrastructure cannot be managed as a collection of individual technical challenges if interdependencies are to be identified and beneficially managed in the infrastructure itself and in delivery programmes. The IP\&MF shall therefore support organisations in recognising and developing their capacity to successfully create and manage interdependencies.

b) The framework shall provide a process for measuring the maturity of an organisation in its approach to interdependency management.

c) The framework shall be founded on a learning process (context-dependent) that also facilitates knowledge management in support of the governance and valuation of infrastructure and associated interdependencies on a continual basis. This is needed in order to support investment proposals in legacy infrastructure, such as upgrades, modifications and asset management and maintenance. 


\section{Requirement Area}

\section{The Framework} Should Reflect Purpose and Support Governance

4. The Framework Shal Provide a Holistic Approach to Measurement and Assessment of Options

\section{Detailed Requirements Specification}

a) The effective and efficient governance or 'stewardship' of infrastructure requires a shift away from an individual asset management perspective, and requires a wide range of institutions and enterprises to collaborate in developing a framework of efficient policies, plans, processes and institutions. The IP\&MF shall be consistent with the principle of stewardship and shared governance of infrastructure.

b) The IP\&MF shall recognise the need for a 'stewardship' role to set planning policies and investment priorities, and respond to turbulence in socioeconomic and natural environments. The IP\&MF shall accommodate and facilitate the identification, appraisal and management of interdependencies now and into the future from the point of view of 'stewards of a continuum' of infrastructure as a system of systems.

c) The IP\&MF should facilitate a collective approach to the governance of infrastructure in a mixed market economy with the goal of breaking the tendency for institutions to retreat into silo-based thinking.

a) Interdependency can be a valuable asset and the IP\&MF shall allow for this to be continually appraised and developed throughout the planning, appraisal, design, and operational life of the related infrastructure.

b) The IP\&MF shall facilitate a means of measuring and assessing the benefits and risks of exploiting interdependencies, and this shall include benefits or costs of the integration that may be external to a given project.

c) The IP\&MF shall provide a means of tracking the success or failure of infrastructure developments, proposed and implemented, against a broad set of measures of performance (soft and hard) with the scope to accommodate both complex and conflicting success criteria.

5. The Framework Shall

a) The framework shall seek to support decision-making in the area of interdependency planning and management, and in particular assist decision-makers cope with wicked planning problems that have open system boundaries.

Decision Making and
Ongoing Project

Management

b) The IP\&MF shall provide a means of supporting evidence-based decisionmaking.

c) The IP\&MF shall allow for known and future uncertainties, associated assumptions, risks and opportunities, and for the evaluation of these.

d) The IP\&MF shall be capable of considering the relative timing of infrastructure development projects and the impacts this has on interdependencies, including the sharing of resources during construction.

(Continued)

6. The Framework Shall Integrate with the

Existing Guidance for

Project Appraisal

Outlined in the HMT

Green Book a) The framework shall work within the context of the existing processes for project appraisal, whilst being flexible enough to work with new approaches to options appraisal. It shall function with CBA and MCA approaches. 


\section{Requirement Area}

7. The Framework Shall Facilitate

Stakeholder Engagement

8. The Framework Shall be Equally Applicable to New and Legacy Infrastructure

\section{Detailed Requirements Specification}

a) The IP\&MF shall in its approach facilitate the need to identify and engage with a broad range of stakeholders and thereby create the potential for innovative new design options encompassing interdependency.

a) Infrastructure comprises a continuum of interconnected systems which is required to meet changing needs in both time and space. Infrastructure delivery projects cannot be conceived in isolation from existing legacy infrastructure, from future known infrastructure needs, or from the developing culture and socio-economic policies within which they exist. The IP\&MF shall therefore be equally applicable to new development and legacy infrastructure systems.

b) The framework shall allow for planners and designers to consider the effect of different design lives for infrastructure development options.

9. The Framework Shall

a) There is considerable professional investment in current infrastructure Recognise Practical Constraints for the Purposes of Implementation appraisal processes and practices exist, including monetised and nonmonetised multi-criteria approaches. A complementary and compatible approach to interdependency planning and management is likely to be more successfully implemented. The IP\&MF shall have the capacity to work with existing economic appraisal approaches.

b) There are varying practical constraints within which infrastructure has to be delivered including, but not limited to, issues of legacy infrastructure, delivering affordability, working within prior planning agreements, and the need for resilience in respect of a wide range of socio-economic, ecological and security hazards. The IP\&MF shall allow for such real-world constraints.

c) In practice, infrastructure development decisions and the evidence needed to support design options with interdependencies (synergies) will need to be collected and refined throughout the ROAMEF life-cycle. It is likely that in the early stages of a project, data to support an appraisal will be presented in a high-level format and may be quite sparse. The IP\&MF will therefore be required to support both 'broad-brush' appraisals at the start of the planning and design processes, as well as more complex and detailed assessments later on in the project life-cycle. 


\section{Appendix B Integrating Multi-Criteria Analysis}

Multi Criteria Analysis (MCA) systems are widely used as methodologies of appraising projects as a basis for decisions on their implementation. MCA systems involve structures which allow quantified and non-quantified indicators to be set out together in a tabulated form, with the aim that decision makers can then gain a complete picture of the implications of a project across all possible fields of impact rather than having them all wound up in one concluding (monetized) figure. It is thus deemed more relevant to the use of project appraisal efforts that seek to assess infrastructure project contributions to sustainable development outcomes. It is also more conducive to facilitating the engagement of project sponsors and investors with other stakeholders, including community groups, in ways that can provide valuable inputs into project design and appraisal including the identification of positive and negative interdependencies. MCA thus contrasts with the CBA approach quite significantly, although there is clear acknowledgement by advocates of MCA that CBA plays an important role within MCA.

MCA is more commonly used for appraisal (and monitoring) processes that do not require a single monetary return or where such a measure is considered impossible or lacking in any useful validity. It is aimed at supporting decision makers who are faced with making numerous and conflicting evaluations that involve monetary and non-monetary assessments. It aims at highlighting both commonalities and conflicts between multiple criteria framing the decision making space and seeking compromise among choices in a transparent process. It is especially important for environmental and social assessments of projects, such as Environmental Impact Analysis (EIA), Social Impact Analysis (SIA) and Sustainability Appraisal (SA). MCA offers a valuable discipline in ensuring that that nonquantifiable project appraisal concerns are included and assessed and represents added value to both:

- the decision process, by helping the decision-maker know more about the decision problem and explore the alternatives available; and

- the decision outcome, by helping elicit value judgements about trade-offs between conflicting objectives.

It furthermore benefits considerably from having as much of the criteria quantified to the maximum extent realistically possible and even monetized where this may be done soundly, without ignoring those aspects that do not lend themselves to quantification or where efforts of quantification incur costs beyond what is affordable.

In broad terms there are usually three distinct phases in MCA development; namely:

- problem structuring,

- model building, and

- the use of the model for informing and challenging thinking.

In more detail, these phases can be broken down as follows:

- The problem structuring phase. This is used to define the terms under which a decision-making problem is considered and stakeholders are to be included into the decision making process. It also involves the collection of information regarding the options and related criteria for decision making to be considered. A combination of deliberative techniques can be used for the active involvement of relevant actors.

- The model building phase. This phase is dedicated to the tasks of defining the criteria and deciding on their relative importance or the values attributed to each of the criteria by different stakeholders. 
- The application of the model. This entails using targets or weights to determine the value of each criterion within the framework or model and scores. It seeks to determine the performance of each alternative with regards to each criterion. It may lead directly to a decision or result in feedbacks to the previous phases that revise the definition of the problem, the choice of criteria, etc.

The DTLR MCA manual [54] highlights that a standard feature of most MCAs, and key point of departure for the varying methodologies, is the performance matrix, sometime referred to as the consequence table. The table is usually laid out in such a way that each row describes an option for decision making and each column describes the performance of each option against a set of criteria. In a basic MCA the performance matrix may be the end product of the analysis, where decision makers are left with the task of assessing the extent to which their objectives are met by the entries in the matrix. More advanced applications of MCA include scoring and weighting to arrive at a ranking of options.

MCA frameworks can contribute significantly to the IP\&MF. Although applicable at all stages in the project life cycle, MCA should ideally be employed very early, preferably in the preliminary stages of developing the project rationale. Here the MCA process can make the largest overall impact on the project by facilitating a shared understanding among different project stakeholders of the project's boundaries, context(s), underlying visions and objectives, project interdependencies and project risks, plus the criteria that might be used in the scoring of project options or scenarios.

In particular the recent findings from the OMEGA Centre, highlight the importance of the role of policy in infrastructure development and necessity for its adequate inclusion within decision making frameworks such as MCA [54] and IP\&MF. Lesson 8 of the OMEGA Findings suggests that MTPs are unlikely to be able to deliver the full range of benefits as 'agents of change' unless accompanied by a suitable institutional, policy and legislative framework that is in place throughout the project lifecycle. The interdependency identification and management frameworks and process should therefore be consistent with these findings. The 'hardwiring' of interdependencies is not enough to achieve a holistic solution, the 'software' such as institutional and legislative support must also be considered (modified/revised, unblocked and created as required).

The interaction of policy and infrastructure development is complex, however as a starting point two basic modes of project initiation may be identified:

Policy Led Infrastructure Development: Policies may be created to facilitate or alleviate particular types of impact, thereby creating direct drivers for particular types of project, for example the UK Thames Tideway Tunnel is an engineering response to the EU Urban Wastewater Treatment Directive.

Non - Policy Led Infrastructure Development: Infrastructure needs may be identified as a result of forces other than direct policy intervention, for example the early proposals for the Jubilee Line Extension were led by private sector developers to increase accessibility to the London Docklands to support the Canary Wharf Phase II development. However the subsequent development of the JLE was heavily influenced by Government Policies. 
The OMEGA centre argues that regardless of the initial project driver, 'policy' or 'non-policy' led there is a necessity for infrastructure project development to take full account of the overarching policy context within which the project is being developed. This enables a link to be established between strategic goals and project objectives. Therefore the infrastructure appraisal framework applied to the project should be 'policy led'. A 'policy informed' MCA would be too akin to current appraisal methodologies where the interests of particular sectors dominate the appraisal process without due regard to a range of important impacts.

Where there are strong and complementary policy guidelines, such as in the case of projects to be appraised by development institutions such as the EIB, these can be directly adopted during the appraisal process. Effectively this type of appraisal is checking that a project is compliant with policy.

In the case where policy guidelines exist but there are inherent contradictions between the various policies framing the infrastructure development, MCA can be used to aid decision makers in identifying the conflicting policies and can facilitate trade-offs to resolve such conflicts where possible, or to agree a weighting scheme to clarify the relative importance of the conflicting objectives. In some cases the appraisal process may highlight the impracticality of a particular suite of policies, for example the widespread adoption of technological innovations to fulfil policies regarding low carbon energy generation may have significant negative impacts concerning visual blight which require revisions to the facilitating policy, therefore the appraisal process may have an explicit or implicit impact on the prevailing policy context through feedback links established in the decision making process. In the cases where policy is under-developed, the MCA framework can expose gaps in the policy context, and the decision making process can be used to directly inform the creation of new policy.

It is most significant to highlight the fundamental importance of feedback links between appraisal and policy as outlined in the above three modes of policy project interaction. Whilst policies should be injected into the decision making process as soon as possible, they should not be seen as a straitjacket which stifles innovation - feedback loops allow incorrect or inefficient policies to be identified and amended as part of the decision making process.

Concerning the mapping from policy onto project purpose using an MCA framework: As a first step it will be necessary to clarify and clearly articulate objectives emanating from the various policies that comprise the overall policy framework. In this regard it is of utmost importance that:

- each policy objective is readily comprehensible to all involved stakeholders and that there is consistent understanding of them in terms of the opportunities or constraints they impose on the appraisal object;

- each policy objective is so constructed as to enable their further translation into appraisal criteria that can be measured in some way - either quantitatively or in a qualitative fashion. Indeed, it is often the case that policy objectives are cited in an all-embracing or rather 'woolly' manner, which tends to make their interpretation rather difficult;

- any potential policy 'gaps' (and thus gaps in the coverage of objectives) should be addressed in conjunction with involved stakeholders;

- thought be given as to whether policy objectives are fully capable of dealing with any scenario conditions that are to be built and tested;

- due regard is had to the hierarchy of objectives that emanate from the broader policy hierarchy - as this may be used to inform subsequent weighting. This should also include the re- 
confirmation and clarification of those policies and objectives that are deemed non-negotiable 'showstoppers, together with the associated implications of this';

- any perceived risks associated with policy objectives are clearly identified and articulated.

Subsequent to the above, there will be a need to identify and articulate appraisal criteria for each key policy objective. It should be noted that, like the above policy objectives, appraisal criteria must be readily understandable and measurable (quantitatively or qualitatively) and that due regard should be had for the overall policy hierarchy. Moreover, each appraisal criteria should be capable of both identifying 'winners and losers' and potential risk sources (and impacts - including the costs and benefits of any mitigation measures) over time and space.

The full application of an MCA usually incorporates 9 steps which are outline below and can be mapped onto the ROMEF framework to form part of the IPM\&F.

- Step 1: Establish the decision context - what are the aims of the MCA and who are the decision makers and other key players.

Establish a shared understanding of the decision context (technical, administrative, political, social, and environmental structures that surround the decision being made). It is important to consider the objectives of the decision making body, the administrative and historical context, the set of people who will be affected by the decision and an identification of those responsible for the decision.

- Step 2: Identify the options.

Once the decision context is established the following step is to list the options to be considered. It may be necessary to carry out some informal sifting of options as it may not be worth data collection/effort for clearly infeasible propositions.

- Step 3: Identify the objectives and criteria that reflect the value associated with the consequences of each option.

The criteria and sub criteria are the measures of performance by which the options will be judged. "A large proportion of the value added by a formal MCA process derives from establishing a soundly based set of criteria against which to judge the options" DTLR (2001) (Updated at [54]). The criteria must be operational and a number of procedures are arrive at workable criteria. One option suggested is a brainstorming session (of key decision makers, and possibly affected parties in some stages of the MCA). Another approach may be to examine policy statements and secondary information sources from the various interest groups and to derive criteria to reflect their concerns. Once criteria are derived it is desirable to group them into a series of sets which related to separate and distinguishable components of the overall objective of the decision. Grouping criteria is an important part of the MCA process, helping to check the relevance of the criteria, ease the process of calculating criteria weights and facilitates the emergence of higher level views of the issues, especially regarding trade-offs between key objectives.

Before finalising the criteria the provisional set of criteria must be assessed against a range of qualities:

1. Completeness - all important criteria included?

2. Redundancy - are there unnecessary criteria?

3. Operational - it is important that each option can be judged against each criterion 
4. Mutual independence - preferences associated with the consequences of options are independent of each other from one criterion to the next

5. Double Counting - it is quite easy for some basic impact to be recorded more than once in a performance matrix

6. Size - avoid an excessive number of criteria

7. Impacts occurring over time - attention should be drawn to time differential impacts

- Step 4: Scoring - Describe the expected performance of each option against the criteria and then score accordingly.

The first step is to describe the consequence of the options, and then to score the options against the criteria. For simple problems the description of performance could be via a performance matrix (see above) whilst more complex problems guidance recommends the use of decision trees. The second step is to score the performance of an option against each of the criteria. As the performance matrix will often contain variety of performance indicators for different criteria (including both quantifiable and non-quantifiable aspects) these different units of measurement cannot be combined directly to achieve an overall evaluation. Therefore scales are constructed to represent preferences for the consequences. The third step is to check the consistency of the scores for each criterion.

- Step 5: Weighting - Assign weights for each of the criteria to reflect their relative importance to the decision.

The preference scales derived in step 4 still cannot be combined because a unit of preference for one criteria does not necessarily equate to a unit of preference for another criteria. Equating the units of preference is equivalent to judging the relative performance of the scales, so with the right weighting procedure, the process is meaningful to those making the judgements. 'Swing weighting' is a common approach applied to MCA.

- Step 6: Combine the weights and scores for each of the options to derive the overall value.

Multiply an options score on a criterion by the importance weight of the criterion, do that for all criteria, then sum the products to give the overall preference score for that option. Then repeat the process for the remaining options. This step usually relies on computer programmes to combine the weighted scores.

- Step 7: Examine the results.

The output from step 6 should be a top level ordering of options given by weighted average. The results of the MCA could be surprising, so it may be necessary to establish a temporary decision system to deal with unexpected results. It is important to leave time for this stage of the analysis.

- Step 8: Sensitivity Analysis. Conduct a sensitivity analysis of the results to changes in scores or weights.

- Step 9: Iterate if required - the MCA is essentially an iterative process. There is no need to get all the inputs to the model correct with the first go. Additional information can be gathered inbetween iterations, and values and weights can be refined throughout the process. 